This item was submitted to Loughborough's Research Repository by the author.

Items in Figshare are protected by copyright, with all rights reserved, unless otherwise indicated.

\title{
Measures of impairment applicable to the classification of Paralympic athletes competing in wheelchair sports: A systematic review of validity, reliability and associations with performance
}

\section{PLEASE CITE THE PUBLISHED VERSION}

https://doi.org/10.1080/02640414.2020.1815957

\section{PUBLISHER}

Taylor \& Francis

\section{VERSION}

AM (Accepted Manuscript)

\section{PUBLISHER STATEMENT}

This is an Accepted Manuscript of an article published by Taylor \& Francis in Journal of Sports Sciences on 10 September 2020, available online: http://www.tandfonline.com/10.1080/02640414.2020.1815957.

\section{LICENCE}

CC BY-NC-ND 4.0

\section{REPOSITORY RECORD}

Hutchinson, Michael, Jamie-Lee Phillips, Barry Mason, Vicky Goosey-Tolfrey, and Emma Beckman. 2020. "Measures of Impairment Applicable to the Classification of Paralympic Athletes Competing in Wheelchair Sports: A Systematic Review of Validity, Reliability and Associations with Performance". Loughborough University. https://hdl.handle.net/2134/12865682.v1. 
1 Title: Measures of impairment applicable to the classification of Paralympic athletes

2 competing in wheelchair sports: A systematic review of validity, reliability and associations

3 with performance.

4

5 Running title: Measures of impairment for Paralympic classification.

6 Authors: Michael J. Hutchinson ${ }^{1}$, Jamie-Lee K. Phillips ${ }^{2}$, Barry S. Mason ${ }^{1}$, Victoria L.

7 Goosey-Tolfrey ${ }^{1}$, Emma M. Beckman ${ }^{2}$.

8

9 Author affiliations: ${ }^{1}$ Peter Harrison Centre for Disability Sport, School of Sport, Exercise 10 and Health Sciences, Loughborough University, Loughborough, LE11 1SB, United

11 Kingdom.

$12{ }^{2}$ School of Human Movement and Nutrition Sciences, University of Queensland, Brisbane, 13 Queensland 4072, Australia.

14

15 Corresponding author: Dr Emma Beckman; E.Beckman@uq.edu.au; +61 733467904

16

17 Word count: 6254

18 Number of tables: 4

19 Number of figures: 1 


\section{Abstract}

21 A fundamental aspect of classification systems in Paralympic sport is having valid and reliable

22 measures of impairment. However, minimal consensus exists for assessing impaired strength,

23 coordination and range of motion. This review aimed to systematically identify measures of

24 upper body strength, coordination and range of motion impairments that meet the requirements

25 for use in evidence-based classification systems in wheelchair sports. Three electronic

26 databases were searched from 2003 until August $31^{\text {st }} 2019$ for studies that assessed upper body

27 function of participants and used a measurement tool that assessed strength, coordination or

28 range of motion. The body of evidence for each identified measure was appraised using the

29 Grading of Recommendations Assessment, Development and Evaluation framework. Twenty-

30 three studies were included: ten measured strength and coordination, and six measured range

31 of motion. There was "moderate" confidence in using isometric strength for assessing strength

32 impairment. Tapping tasks for the assessment of coordination impairment received a "low"

33 confidence rating. All other identified measures of coordination and range of motion

34 impairment received a "very low" confidence rating. Several potential measures were

35 identified for assessing upper body strength, coordination and range of motion impairments.

36 Further research is warranted to investigate their use for classification in Paralympic

37 wheelchair sports.

38 Keywords: strength, coordination, range of motion, classification, Paralympics 


\section{Introduction}

An integral part of Paralympic sport is classification, the purpose of which is to minimise the impact of eligible impairment types on the outcome of competition [1]. Each Paralympic sport requires its own classification system, which groups athletes according to the level that their impairment impacts on performance in that particular sport. This is to ensure that characteristics such as talent, volume and quality of training, and psychological factors are the determinants of success in Paralympic sport, rather than severity of impairment [1]. Further to the need for each classification system to be sport-specific, the classification code of the International Paralympic Committee (IPC) also requires these systems to be evidence-based in all Paralympic sports [2] which means that the methods used to allocate class must be based on science that supports the system and demonstrates that the aim of classification is achieved. For the development of evidence-based classification systems, sports and researchers must: 1) specify the eligible impairment types; 2) develop valid measures of impairment; 3) develop standardised, sport-specific measures of performance; and 4) assess the strength of association between the measures of impairment and performance [3].

There are ten impairment types eligible for competition in Paralympic sports: impaired muscle power, impaired range of motion (ROM), hypertonia, ataxia, athetosis, leg length difference, limb deficiency, short stature, visual and intellectual impairment [1]. Hypertonia, ataxia and athetosis all affect motor coordination. Paralympic sports are able to specify which of the ten eligible impairment types they are to include within their classification system. Once this determination is made, a primary issue of importance for all sports is to ensure they use appropriate methods for assessing impairment. The IPC position stand on classification stipulates that methods for assessing impairment should be: objective (ratio-scaled), reliable, parsimonious, impairment-specific, sport-specific and resistant to training [3]. 
Examples of three Paralympic sports that are working towards evidence-based classification systems are wheelchair basketball, wheelchair rugby and wheelchair tennis. For these sports the eligible impairments are: impaired muscle power (strength impairment), impaired ROM, hypertonia, ataxia, athetosis, leg length difference and limb deficiency [4-6]. Though it is likely that function of the lower limb will contribute to sports performance, observation of the sports highlights that assessment of upper body and trunk impairment is likely to be of fundamental importance to their classification systems. Wheelchair tennis involves high velocity wheelchair propulsion and mobility, racket grip strength, powerful overheard service and a strong forehand and backhand [7,8]. Wheelchair basketball and wheelchair rugby also require high velocity wheelchair mobility performance, as well as ball handling skills such as passing, catching and dribbling. These aspects of performance will all be impacted by impairments to strength, coordination (hypertonia, ataxia and athetosis) and ROM of the upper body and trunk. This emphasises the requirement for methods of assessing these impairment types based on the varying determinants of performance in the different sports.

The need is further highlighted by investigating the existing classification systems of the sports. Current classification processes for wheelchair rugby and wheelchair tennis do include measures of impairment, however they are most often clinical measures relying on expert opinion. For example, strength impairment is currently assessed using manual muscle testing $[5,6]$. This method uses an ordinal scale and previous research has demonstrated unacceptable inter-rater reliability [9], making it unsuitable for use as part of an evidence-based classification system. Furthermore, no specific methods for assessing upper body coordination impairment are provided within current classification manuals $[5,6]$ and whilst eligibility criteria exist for classifying static ROM impairment [5,6], there is no guidance for what method(s) to use, or whether dynamic tests should also be included. In contrast to wheelchair rugby and wheelchair 
tennis, wheelchair basketball uses a functional classification system that assigns a sports class based on observation of an athlete's volume of action in performing fundamental activities during training and match play [4]. As such, there is no direct assessment of an athlete's level of impairment, as required by evidence-based classification. This most likely contributed to the decision of the IPC in January 2020 to deem the International Wheelchair Basketball Federation as non-compliant with the classification code and, as of June 2020, be stripped of the sport's place at the 2024 Paralympic Games [10].

In order to aid the development of evidence-based classification systems in wheelchair sports, potential methods for assessing upper body strength, coordination and ROM impairments need to first be identified. Once identified, their use as part of sport-specific classification systems can then be investigated, including by studying the association with determinants of sports performance. Therefore, the principal aim of this review was to systematically identify methods for assessing upper body (including trunk) strength, coordination and ROM impairment that could be used for the development of evidence-based

102 classification systems in wheelchair sports. A subsequent aim was to investigate, for each

103 identified method, the validity for it to measure impairment, the test-retest reliability and the association between impairment and sports performance.

\section{Methods}

This review was undertaken in accordance with the Preferred Reporting Items for

107 Systematic Reviews and Meta-analyses (PRISMA) guidelines [11]. The PRISMA checklist for this review can be found in Supplement 1. This review protocol was not registered.

\subsection{Information sources}

110 Studies were identified by searching three databases: PubMed, Web of Science and 111 SPORTSDiscus. In addition to database searches, a manual search of personal databases and 
112 reference lists of included studies were undertaken to identify studies and grey literature that

113 did not appear in the databases listed above. Two key searches were used to distinguish between

114 Para sport and non-Para sport studies for use in Paralympic classification. Two different

115 searches were undertaken to differentiate between studies that had already been evaluated for

116 use in Paralympic sport and studies that have been conducted in a clinical context to assess an

117 impairment that is also eligible for wheelchair sport.

118 For all databases the search for Para sport was: Paralympic AND sport AND classif*

119 AND (test OR measure OR assess) AND impairment. For non-Para sport the search strategy

120 employed was: (ataxia OR athetosis OR hypertonia) AND (test OR measure OR assess OR analys*) AND (strength OR coordination OR range)) NOT rehabilitation.

Specific strategies were employed for each database. In PubMed "ataxia", "athetosis" and "hypertonia" were searched as MeSH terms, whilst for Web of Science the search terms were applied to all fields. For the search in SPORTSDiscus the option to search within the full text was selected. Searches were conducted from 2003 up to $31^{\text {st }}$ August 2019, based on discussions with an academic librarian.

\subsection{Study eligibility}

128 Studies that met the following criteria were included in the present review:

- Examined assessment methods of upper body (including trunk) impairment that have been tested for the use in Paralympic sport.

- Examined clinical measurements or novel tests that assess eligible impairment types for Paralympic sport: strength, coordination or ROM.

- Participants between the age of $15-55$ years old $( \pm 5 \%)$. Age range selected to represent the competition age of a typical Paralympic athlete. 
- Published as a full-text article in English, in a peer-reviewed journal.

136 Studies that contained no upper extremity components (i.e. examining lower extremity only); were older than 15 years; or that assessed strength, coordination or ROM in non-disabled participants unless designed to inform Paralympic classification were excluded from this 139 review.

\subsection{Eligibility screening}

Two reviewers (Authors $1 \& 2$ ) conducted eligibility screening independently, with differences assessed at each stage. Consensus was reached through discussion with the corresponding author (Author 5). Studies were screened in two stages: title screening and full text screening. Titles were excluded that clearly did not meet eligibility criteria. The full texts of remaining articles were then reviewed, with reasons for exclusion recorded.

\subsection{Data extraction}

One reviewer (Author 2) performed the data extraction of included studies, which was checked by a second reviewer (Author 1). The following data was extracted from each study:

149 (1) author/s and publication year (2) objective of the study (3) sample size, sex and age (4)

150 description of the sample size (5) Measurement focus (strength, coordination or range of motion) (6) Assessment tool/technique and method of data collection (7) outcome measures (8) results. In studies examining both upper and lower body, only the information relevant to the upper body was included in the review.

\subsection{Risk of bias and quality assessment}

All included studies were assessed for risk of bias and quality assessment using a modified appraisal tool for cross-sectional studies (AXIS) [12], eliminating the questions not relevant to the included studies. The modified tool includes 17 questions assessing various 
158 factors of quality and bias. The questions were answered yes, no, unclear or not reported for 159 each study.

160 For each identified method of assessing strength, coordination or ROM impairment an 161 evidence summary was produced. Subsequently, the Grading of Recommendations, 162 Assessment, Development and Evaluation (GRADE) framework [13] was used to assess the 163 body of evidence for each identified method and to assign a confidence rating in the body of

164 evidence. Evidence was assessed for i) risk of bias, ii) inconsistency, iii) imprecision, iv) 165 indirectness and v) publication bias in accordance with published procedures [14-18], resulting 166 in a confidence rating ranging of "very low", "low", "moderate" or "high" for the evidence

167 found. The body of evidence for each method begins with an initial "high" confidence rating, 168 with a stepwise down-grading for the existence of any of the 5 aforementioned assessment 169 factors [13].

\section{$170 \quad 3 \quad$ Results}

\subsection{Literature search}

The electronic search produced 3595 records. After removing duplicates, 2916 studies remained. The title of each study was screened, and 147 potential studies were archived. After reading the full text of each study, 23 were included and 124 excluded from the review. A flow chart depicting the study selection process is shown in Figure 1.

\subsection{Description of included studies}

Of the 23 included studies, 10 investigated methods for assessing strength impairment 178 [19-28], 10 coordination impairment [23,29-37] and 6 ROM impairment [25,29,38-41].

179 Studies investigating strength impairment had a combined sample of 382 participants, 180 comprising 234 disabled participants (9 studies) of which 201 were Para-athletes (8 studies), 
and 148 non-disabled participants ( 2 studies). Coordination impairment was investigated in a total of 414 participants, of which 288 were disabled (8 studies; 94 Para-athletes across 2 studies) and 126 were non-disabled (5 studies). For ROM a total of 173 participants were

184 investigated: 110 disabled (6 studies; 94 Para-athletes across 5 studies) and 63 non-disabled (3

185 studies). Extracted data are presented for studies investigating strength (Table 1), coordination 186 (Table 2) and ROM (Table 3) impairments.

\section{$187 \quad 3.3 \quad$ Methods for measuring strength impairment}

The methods identified for measuring upper body strength impairment were isometric

189 strength, handgrip dynamometry and trunk stability, both static and dynamic (Table 1).

190 Isometric strength using a load cell was investigated in seven studies [19-22,24,25,28],

191 handgrip dynamometry in four [21-23,25] and trunk stability in three [20,26,27]. In terms of

192 the type of analysis employed by studies, eight assessed the validity for it to measure

193 impairment [19-24,26,27], three investigated the test-retest reliability of the method

$194[21,23,24]$, and five investigated the association between the measure of impairment and

195 performance [19,22,24,25,28].

\subsubsection{Isometric strength}

Regarding the validity of isometric testing for measuring impairment, cluster analysis of several isometric strength tests was able to produce clusters of athletes with similar levels of

199 activity limitation in a group of wheelchair track racing athletes [22]. Similarly, random forest

200 algorithm correctly classified $95 \%$ of Para-swimmers based on shoulder flexion and extension

201 isometric strength [24]. Isometric strength was shown to be highly reliable (Intraclass

202 Correlation Coefficient (ICC): 0.71-0.95 [21]; 0.94-0.97 [24]) across various upper body

203 movements in non-disabled participants. 
Measures also need to be evaluated by investigating their relationship with performance.

In a study of wheelchair rugby players, isometric trunk flexion strength was shown to

significantly correlate with wheelchair propulsion acceleration performance [19], whilst isometric shoulder extension strength significantly correlated with freestyle swim speed in Para-swimmers [24]. Arm extension, trunk flexion and combined arm-trunk strength also correlated with top speed in wheelchair racing propulsion across a group with different sport classes [22], however trunk flexion strength did not correlate with acceleration performance in

211 athletes with the same classification [28].

Using the GRADE framework to assess the evidence for using isometric strength, results in a "moderate" confidence rating. There are consistent findings for the valid and reliable use

214 of isometric strength tests across a number of different sports, whilst the evidence shows good

215 directness as the evidence is in Para-athletes. Though the findings are consistent across sports,

216 there are only isolated studies within each sporting example, so these results in themselves lack 217 corroboration.

\subsubsection{Handgrip dynamometry}

Validity of handgrip dynamometry is demonstrated by the significant differences in

220 handgrip strength between adjacent classes produced by cluster analysis [22]. Handgrip strength was also shown to be reliable in patients with spastic ataxia (ICC: 0.97 and 0.98; Standard error of measurement: 1.6 and $1.3 \mathrm{~kg}$ for right and left limb, respectively) [23]. Finally, handgrip strength was shown to correlate with absolute top speed $(r=0.79)$ in elite wheelchair racers [22] and hand release speed $(r=0.59-0.77)$ in seated throwers [25]. handgrip dynamometry. There is inconsistency due to a lack of corroborating studies assessing 
of bias regarding the reliability as it has only been investigated in a single study [23]. This study also shows indirectness as it was in a non Para-athlete population.

\subsubsection{Trunk stability}

For investigations of trunk stability, static balance was not different amongst wheelchair rugby players based on an ordinally-scaled Trunk Impairment Classification system [20]. However, dynamic limits of stability during maximal trunk leaning were significantly greater in athletes with less trunk impairment [27]. Furthermore, trunk stability was greater during perturbations in sit-skiers with lower levels of trunk impairment [26]. There were no studies investigating the reliability, or association with performance, of trunk stability.

Evidence into dynamic trunk stability assessments contain a risk of bias due to small samples sizes of studies and the lack of corroborating evidence, meaning there is no consistency of results. The test-retest reliability of the method remains to be investigated also. Though there

240 is good directness through the use of Para-athletes, overall there is "very low" GRADE confidence in the use of trunk stability assessment.

\subsection{Methods for measuring coordination impairment}

Methods identified for measuring upper body coordination impairment were tapping

244 tasks, standardised finger to nose test (SFNT), Archimedes spiral, box and block test (BBT), 245 nine-hole peg test (9HPT) and Purdue pegboard (PP) (Table 2). Tapping tasks were 246 investigated in four studies [31,33,36,37], SFNT [23,34,35], BBT [32,34,37] and 9HPT

$247[23,32,35]$ in three studies each, with the Archimedes spiral $[23,30]$ and PP $[34,35]$ investigated 248 in two studies. Regarding the type of analysis, eight investigated the validity of the method for 249 measuring impairment [23,29,30,32,34-37], six the test-retest reliability of the method [23,31- 
$25033,36,37]$, and two investigated the association between the measure of impairment and 251 performance $[36,37]$.

\section{$252 \quad 3.4 .1 \quad$ Tapping tasks}

Regarding the validity of tapping tasks for measuring impairment, random forest algorithm correctly classified $96 \%$ of either non-disabled or Para-swimmers, with reciprocal tapping task performance significantly correlating with freestyle swim speed [36]. A reciprocal vertical tapping task was also able to distinguish between adjacent sport classes in boccia players [37]. Tapping tasks were shown to be reliable in non-disabled participants $[31,33,36]$, though reciprocal (ICC range 0.54-0.93) tapping tasks showed lower ICC compared to discrete tasks (ICC range 0.85-0.92) [31]. Furthermore, using Fitts' Law, deliberate submaximal performance, also known in the classification process as Intentional Misrepresentation (IM), could be detected using tapping tasks [33].

GRADE assessment results in a "low" confidence rating for the use of tapping tasks.

263 Evidence for tapping tasks contain a small risk of bias due to the small sample sizes. Findings in Para-athletes are consistent, but are limited to two sports, whilst test-retest reliability has only been investigated in non-disabled participants resulting in indirectness.

\subsubsection{Archimedes spiral}

The assessment of a computer-based Archimedes spiral test was piloted for the first time and was found to be a valid way of measuring coordination impairment, correctly classifying 96\% of patients with ataxia based on the mean error result [30]. There were no studies investigating the reliability, or association with sport performance, of the Archimedes spiral test. 
GRADE assessment results in a "very low" confidence rating for the evidence on

273 Archimedes spiral. There is a lack of evidence on the test-retest reliability, as well as the

274 relationship between impairment and sport performance. Furthermore, there is a lack of 275 corroborating evidence for the validity of the Archimedes spiral, whilst there is also a lack of 276 evidence in Para-athletes.

\subsubsection{Standardised finger to nose test}

The SFNT showed excellent inter- (ICC range 0.90-0.98) and intra-rater reliability (ICC range $0.93-0.97$ ) in patients with ataxia [23] whilst also being able to discriminate based on disease stage $[34,35]$. There were no studies investigating the relationship between SFNT and sport performance.

GRADE assessment results in a "very low" confidence rating for the use of the SFNT. Whilst there is good evidence for its reliability, this is limited to a single study. Furthermore, there is a lack of evidence in Para-athletes.

\subsubsection{Box and block test}

Performance on the BBT was shown to have a negative correlation with disease duration patients with Friedrich ataxia [32]. The BBT, as well as a modified version using Boccia balls instead of blocks, were also able to distinguish between non-disabled participants and Boccia athletes of different classifications [37]. There were no studies investigating the reliability, or association with sport performance, of the BBT.

There is "very low" confidence in the evidence for using the BBT. There is a lack of

292 corroborating evidence for the validity of the test, whilst there is only a single study performed in Para-athletes [37]. 


\subsubsection{Nine-hole peg test}

9HPT was able to distinguish between disease severity [23,35] and disease duration [32]

296 in patients with ataxia. The standard error of the measurement was found to be $6.5 \mathrm{~s}$ and $7.1 \mathrm{~s}$

297 for performance with the right and left hand, respectively [23]. No studies investigated the association between performance on 9HPT and sport performance.

GRADE assessment results in a "very low" confidence rating for the 9HPT. This is due to inconsistency resulting from a lack of corroborating evidence, and a lack of studies in Paraathlete groups.

\subsubsection{Purdue pegboard}

Performance on PP was significantly correlated $(r=0.82)$ with performance on SFNT

304 [34]. The PP was also able to distinguish between disease severity in patients with ataxia [35]. There were no studies investigating reliability, or association with sport performance, of the PP.

GRADE assessment results in a "very low" confidence rating for the PP. This is due to inconsistency resulting from a lack of corroborating evidence, and a lack of studies in Paraathlete groups.

\subsection{Methods for measuring range of motion impairment}

The methods identified for measuring ROM impairment were an inclinometer, goniometer, motion capture system and video analysis (Table 3). Inclinometer and goniometer

313 were used in a single study [40], motion capture was used in four studies [25,29,38,41], and

314 video analysis in one study [39]. Five studies investigated the ability of the method to measure 315 impairment [29,38-41], a single study investigated the test-retest reliability of the method [40], and two studies investigated the association between impairment and performance $[38,41]$. 


\subsubsection{Inclinometer and goniometer}

Elbow flexion and extension, as well as shoulder internal and external rotation were able

319 to distinguish non-disabled from Para-swimmers [40]. Reliability for measuring upper

320 extremity ROM in non-disabled participants was shown to be good to excellent and slightly

321 better for inter-rater reliability when using an inclinometer (ICC range 0.75-0.90) compared to

322 goniometer (ICC range 0.67-0.79) [40]. No studies investigated the association between ROM

323 impairment measured using an inclinometer or goniometer and sport performance.

There is "very low" confidence in the evidence for the use of an inclinometer or goniometer. There is a risk of bias due to small sample sizes, whilst there is also inconsistency due to the small number of included studies. Though there is evidence in Para-athletes, this is limited to a small number of sports.

\subsubsection{Motion capture}

Kinematic analysis when using a motion capture system showed that trunk flexion and trunk/pelvis rotation was significantly different between non-disabled and Para-kayak athletes with increasing levels of impairment, whilst these variables also correlated with power output when paddling [38]. Trunk inclination and elbow flexion were also shown to be significantly different between boccia players of different classification [41]. There was also a moderate positive correlation $(\mathrm{r}=0.53)$ between elbow extension $\mathrm{ROM}$ and ball release speed in boccia players [41].

GRADE assessment results in a "very low" confidence rating for the use of motion capture systems. Studies have a small sample size whilst there is limited corroborating

338 evidence. Though studies are in Para-athlete populations, the number of sports studied is 339 limited. 


\subsubsection{Video analysis}

It was found that trunk ROM was significantly greater in wheelchair fencing athletes

342 with less impairment during maximal lunge and fast-return actions [39]. However, no studies investigated the reliability of measuring ROM via video analysis, or the association between

344 ROM from video analysis and sport performance.

GRADE assessment results in a "very low" confidence rating for using video analysis

There is a risk of bias due to the small sample size of the study, whilst there is no corroborating

evidence. There is also no evidence as to the test-retest reliability of the method for measuring impairment, or investigations into the relationship between impairment and sport performance using this method.

\subsection{Risk of bias and quality assessment within studies}

The risk of bias and quality assessment of the fourteen included studies according to the modified AXIS tool is shown in Table 4. All studies demonstrated minimal risk of bias using appropriate research designs, participant selection and recruitment. However, only two studies, one of which was included twice as it investigated coordination and ROM, provided a power calculation to justify their sample size $[21,29]$.

\section{Discussion}

To develop evidence-based classification systems, identifying methods of measuring

358 impairment is necessary in formulating a test battery [42]. These methods subsequently need

359 to be investigated for their validity in measuring impairment, test-retest reliability, and 360 association with performance. The literature base for Paralympic classification is limited. This makes it difficult to draw clear conclusions about how measures of impairment trialled for use in other sports may be adapted for sports such as wheelchair basketball, wheelchair rugby and 
363 wheelchair tennis. Despite this, all Paralympic classification protocols should abide by the

364 same policies and procedures governing the use of evidence-based classification protocols.

365 Therefore, the current base of evidence-based studies in addition to other clinical tests of

366 impairment can aid in formulating improved classification protocols for wheelchair sports;

367 ultimately leading to additional evidence-based research relevant to Paralympic sport.

\section{$368 \quad 4.1 \quad$ Measures of strength impairment}

In terms of methods for measuring strength impairment, this review found isometric strength to be the most commonly reported measure. Current practices utilise manual muscle testing $[5,6]$ however, the validity and reliability for measures of isometric strength across all included studies far outweighs the subjectivity and ordinal scaling of manual muscle testing. Recent literature has also demonstrated that isometric strength provides the best measure of voluntary maximal contractile strength and is more resistant to training when compared to isokinetic and isotonic testing [9]. This is an important factor to consider when the goal is to measure impairment as part of an evidence-based classification system. to excellent test-retest reliability, an important feature of testing to permit further investigation in Para-athletes [21]. Overall, isometric strength showed strong correlations with activity

380 limitation and acceptable reliability across the included studies (Table 1). Low to moderate correlations found between swim speed and isometric strength in Paralympic swimmers highlights the importance of accounting for all joints involved in swimming, as upon reflection, key strength measures relevant to swimming were missed in the isometric test battery [24]. A

384 possible explanation for these findings could be due to the fact that only a single-joint measurement of strength was conducted. A better method would be to use multi-joint measures in order to account for a greater amount of the variance in sports performance [9]. 
A study involving both single and multi-joint strength measures was able to produce valid wheelchair racing class structures, using cluster analysis techniques [22]. However, though isolated arm (dominant and non-dominant) and trunk flexion strength $(\mathrm{r}=0.54, \mathrm{p}<0.05)$ significantly correlated with top speed during wheelchair propulsion, combining arm push with trunk flexion led to a stronger relationship $(r=0.73, p<0.05)$ than the isolated trunk strength measure [22]. Furthermore, isolated trunk flexion strength was only significantly greater in Cluster 4 compared to Clusters 1-3, whereas combined arm-trunk strength was significantly different between each cluster [22]. Due to the multi-joint nature of wheelchair racing propulsion performance, the combination of arm extension with trunk flexion likely contributed to the heterogeneity of the classes produced, due to the greater complexity of strength analysis. Despite this, overlap in clusters was still observed between strength and activity limitation, highlighting the complex nature of classification. Further studies will be required to assess what joint combinations best reflect activity limitation in wheelchair sports when measuring isometric strength with a load cell. This is because wheelchair racing simply requires forward propulsion, but the multidirectional nature of wheelchair court sports also require braking and backwards propulsion manoeuvres.

Attention also must be given to the joint positions used for the measurement of isometric strength [1]. In Para-swimmers shoulder extension strength showed a moderate correlation with freestyle swim speed, with strength assessed in the joint position corresponding to the start of the underwater pull-phase [24]. Within wheelchair sports, actions can occur in a range of different joint positions. For example, in wheelchair tennis the position of the shoulder will be different for service and forehand strokes, as well as for wheelchair propulsion. Research will need to consider the actions that contribute to wheelchair sports performance and the positions that these occur in for future investigations assessing strength impairment in wheelchair sport. 
412 also identified as a method for measuring strength impairment $[21,23,25]$. Grip strength was

413 found to have one of the strongest correlations with hand speed release in seated throwing 414 sports [25], and was a valuable measurement of strength in combination with pronation 415 measured by a load cell [22]. Grip strength is especially important in wheelchair tennis for both 416 racket grip and wheelchair push grip, thus, is likely to be a useful form of strength measurement 417 for this sport. The inclusion of combining grip strength with pronation/supination strength is related to racket control and should be further explored.

Measurement of static and dynamic trunk stability was a further measure of strength impairment utilised in the existing literature, though is also a term that has been used extensively in relation to the assessment of ROM and balance. Dynamic trunk control was shown to be suitable for identifying wheelchair rugby [20,27] and sit-ski [26] athletes with different levels of trunk strength. Dynamic trunk control would conceivably be advantageous for ball handling performance in wheelchair basketball, particularly if involving collisions with opponents, whilst also contributing to force generation during ball striking in wheelchair tennis. Therefore, it would be of interest to investigate this further in these sports. However, the methods including force platforms and three-dimensional kinematic analysis may not be the most practical for use in classification. Nevertheless, the assessment of trunk impairment will likely be a key feature for many Paralympic sports, and it will be important that future research identifies the specific impairment that they are addressing with each test, be it strength, coordination, ROM.

\subsection{Measures of coordination impairment}

Though methods for assessing athlete's with strength impairment are advised upon, current classification measures of coordination impairment are not clearly defined in the 
435 classification manuals of wheelchair sports [4-6]. Several tests, such as the finger to nose, fast 436 elbow flexion/extension and fast forearm supination/pronation are 'suggested' [6]. These tests

437 can provide visual information about incoordination; however, the missing element of ratio 438 scaling and the apparent freedom of test choice does not meet the standards of Paralympic 439 classification [1].

The use of instrumented tapping tasks is a newly established way of resolving this issue

441 for Paralympic classification. These tests produce ratio scaled measures that allow the 442 determination of how much impairment severity impacts on performance. Indeed, the validity and reliability of various tapping tasks have been widely documented [31,33,36,37], though

444 reliability was better for tasks with a larger target area $(0.12$ versus $0.05 \mathrm{~m})$ [31]. Further research needs to investigate tapping tasks in larger samples of Para-athletes and to investigate

446 the association of tapping task performance with measures of sports performance.

447 Incorporating sport-specific tapping tests also needs to be considered. Wheelchair propulsion 448 is a repetitive action requiring repeated coordination of shoulder, elbow and wrist movements, 449 meaning reciprocal tapping tasks may be most appropriate for use. Conversely, actions such as 450 ball striking in wheelchair tennis, passing in wheelchair rugby and shooting in wheelchair 451 basketball consist of a single coordinated movement, so may be better represented by a discrete 452 tapping task. Such an approach was used in designing tapping tasks for use in Para-athletics, with various reciprocal tasks classed as "wheelchair specific" and discrete tasks as "throwing specific" [31]. Furthermore, in wheelchair tennis both unilateral (dominant/racket hand) and bilateral coordination is important for racket control and wheelchair propulsion respectively. In Para-swimmers unilateral tapping (dominant and non-dominant limb), but not bilateral upper

457 limb tapping, significantly correlated with maximal freestyle swim speed [36]. This was found 458 despite the apparent greater similarity with freestyle swimming of the bilateral tapping task, and could have been due to differences in technique used [36], an aspect that must therefore be 
considered for future investigations. This study also showed that dominant limb tasks showed 461 greater reliability and correlation with freestyle swim speed than non-dominant tasks [36]. In

462 the context of swimming, it is proposed that this result could be due to compensation from the 463 dominant limb during the freestyle action if it is significantly less impaired than the non464 dominant limb [36]. The use of tapping tasks are yet to be researched within the context of 465 evidence-based classification for wheelchair sports, however existing findings in other 466 Paralympic sports demonstrate their potential. They also highlight how researchers will need to consider factors such as: target size; reciprocal and/or discrete movements; unilateral and/or bilateral movements and dominant and/or non-dominant limb use when developing tests. These will need to be applied on a sport-specific basis through considering the key determinants of performance in each sport. in classification [33]. IM is when an athlete deliberately underperforms during classification in order to be placed in a sports class alongside athletes with a greater level of impairment than they actually possess [3]. The difficulty of a tapping task can be calculated by factoring the size of, and the distance between, the two targets [43]. Fitts' Law then states i) that as difficulty increases there is a linear increase in the movement time between the two targets, and ii) that

477 for tasks of equal difficulty, but different combinations of target size and distance between 478 targets, movement times should be equal [43]. Subsequently, conformity with Fitts' Law during 479 a tapping task would satisfy the requirement of maximal performance, with IM being detected 480 if these conditions were not met [33]. Submaximal performance, mimicking IM, could be 481 detected in non-disabled participants during tapping tasks. Such a study needs to be performed 482 in Para-athletes with impaired coordination to investigate if Fitts' Law can be applied for the 483 purpose of detecting IM during classification. Indeed, future research on any method for 
assessing impairment needs to consider the extent to which it may be susceptible to IM and what tools may be available in order to aid detection.

Further to the use of instrumented tapping tasks, the development of a computer-based, objective Archimedes spiral test could also be promising for the future of Paralympic coordination classification. This test, which produces mean spiral tracing error demonstrated significant differences between Para-swimmers and non-disabled participants, of which 96\% were correctly classified [30]. The paper and pen version of the test relies on calculating maximum error by manual measurement. The ability to calculate mean error electronically and the elimination of pen grasp strength warrants further investigation into the possibility of using this test in Paralympic classification.

Despite these findings regarding instrumented tasks, there may still be a place for clinical tests such as the SFNT for use in sports classification. The SFNT is a reputable test and has shown excellent validity and inter- and intra-rater reliability for the purpose of discriminating between ataxia impairment severity [23]. This test may be more applicable to wheelchair tennis as aiming for the finger of the tester has similarities with aiming for a tennis ball, a small object, with a racket. The reliability of the 9HPT is unclear, with concerns that the greater the impairment of an individual, the less chance this test could be repeated reliably on another occasion [23,32]. Additionally, not all participants could complete the test due to difficulty, which poses another problem for those with higher severity of impairment.

\subsection{Measures of range of motion impairment}

ROM is traditionally measured with either an inclinometer or goniometer. In existing classification systems, passive ROM is measured using a goniometer and/or video evidence impaired muscle power showed good to excellent intra and inter-rater reliability which 
exceeded the reliability of using a goniometer [40]. This study also used active ROM measurement in contrast to passive ROM. As an athlete must actively move their body through range during competition, active ROM is likely to be a better indicator of resultant activity

511 limitation. This was the only study found that directly examined ROM measurement. An 512 alternate method of measuring ROM using motion capture appeared in four studies

$513[25,29,38,41]$. Though the specific aims of these studies were not to measure ROM impairment, motion capture was shown to be able to detect differences in ROM between Boccia sport classes during performance [41], as well as non-disabled kayak athletes and Para-kayakers with different sport classes [38]. To the best of our knowledge, the validity and reliability of the use

517 of this type of technology has not been tested for use in Paralympic classification. Given that

518 classification typically occurs away from a laboratory at sporting events, it could be that using motion capture is not a feasible method for classification purposes. However, it still warrants investigation as a method for classifying ROM impairment. This is because if it is shown to be superior to other methods for this purpose, then it may be that existing logistical practices for classifying athletes need to be reconsidered. As such, future studies should determine whether

523 3D kinematic analysis is a practical way of classifying ROM impairment in Paralympic athletes. Future research could also investigate the validity of devices such as inertial measurement units, against 3D motion analysis systems, as these portable, less expensive devices could also serve as a more practical solution for ROM classification.

\subsection{Limitations}

The tight inclusion and exclusion criteria used in this study may have eliminated useful and informative studies from the review. This is especially true of the age range and clinical status of individuals. However, it is also important to acknowledge that without these strict

531 criteria, the amount of studies would have been boundless. This is due to the amount of studies 
532 focusing on the assessment of the impairment types in healthy individuals, as well as

533 individuals aged under 15 or over 55 years. Our best efforts were made to identify databases

534 and search terms relevant to the subject matter, however, it is possible that studies may have

535 been found in other databases not searched. The addition, elimination or rewording of the

536 search terms may also have identified a greater number of studies.

\section{$537 \quad 4.5 \quad$ Future recommendations for research}

Alongside the results and conclusions of this systematic review, we feel that the following recommendations can help guide future research into measures of impairment in

540 Paralympic Sport:

- Increased focus on investigating populations of interest (i.e. Para-athletes) and minimising the reliance on using non-disabled participants.

- Investigation of the test-retest reliability of measures of impairment in Paraathletes.

- Greater number of investigations into the relationship between measures of impairment and sports performance.

- Consideration of how susceptible measures of impairment may be to IM, as well as how IM could be detected with each method of measuring impairment.

- Consideration of how a method of measuring impairment could be practically implemented as part of a classification system.

- Consideration of impairment and health condition specific contexts such as how elements such as fatigue, training and outdoor environments may affects classification methods. 


\section{Conclusion}

Twenty-three studies investigating methods for measuring strength, coordination and

556 ROM impairment as part of evidence-based classification were found. Across all methods,

557 other than isometric strength for which there was "moderate" support, there was "very low"

558 confidence in the evidence for their use in evidence-based classification. That said,

559 instrumented tapping tasks and computerised Archimedes spiral for measuring coordination

560 impairment and using an inclinometer for measuring ROM impairment show promising results

561 and warrant further investigation. Future research should investigate the identified methods

562 with the aim of developing sport-specific, evidence-based classification systems in wheelchair

563 basketball, wheelchair rugby and wheelchair tennis. 


\section{Disclosure statement}

565 The research was supported by funding from the International Tennis Federation. We also

566 thank the travel grant from the Institute of Advanced Studies at Loughborough University for

567 initiating the partnership between the institute involved. The authors have no conflicts of 568 interest that are directly relevant to the content of this review.

569 


\section{References}

571 1. Tweedy SM, Vanlandewijck YC. International Paralympic Committee position stand-

572 background and scientific principles of classification in Paralympic sport. Br J Sports Med. $573 \quad 2011 ; 45: 259-69$.

574 2. International Paralympic Committee. IPC Athlete Classification Code [Internet]. 2015

575 [cited 2019 Aug 21]. Available from:

576 https://www.paralympic.org/sites/default/files/document/170704160235698_2015_12_17\%2

577 BClassification\%2BCode_FINAL2_0.pdf

578 3. Tweedy SM, Beckman EM, Connick MJ. Paralympic classification: Conceptual basis,

579 current methods, and research updates. PM\&R. 2014;6:S11-7.

580 4. International Wheelchair Basketball Federation. Official player classification manual

581 [Internet]. 2014 [cited 2019 Sep 24]. Available from: https://iwbf.org/wp-

582 content/uploads/2017/09/CLASSIFICATION-MANUAL-2014-2018-ENGLISH-FINAL.pdf

583 5. International Wheelchair Rugby Federation. IWRF classification manual [Internet]. 2015

584 [cited 2019 Sep 24]. Available from:

585 https://www.iwrf.com/resources/iwrf_docs/IWRF_Classification_Manual_3rd_Edition_rev586 2015_(English).pdf

587 6. International Tennis Federation. Wheelchair Tennis Classification Rules [Internet]. 2019

588 [cited 2019 Aug 21]. Available from: https://www.itftennis.com/media/309472/309472.pdf

589 7. Cavedon V, Zancanaro C, Milanese C. Kinematic analysis of the wheelchair tennis serve:

590 Implications for classification. Scand J Med Sci Sports. 2014;24:e381-388.

591 8. Moon H-B, Park S-J, Kim A-C, Jang J-H. Characteristics of upper limb muscular strength 
592 in male wheelchair tennis players. J Exerc Rehabil. 2013;9:375-80.

593 9. Beckman EM, Connick MJ, Tweedy SM. Assessing muscle strength for the purpose of

594 classification in Paralympic sport: A review and recommendations. J Sci Med Sport. $595 \quad 2017 ; 20: 391-6$.

596 10. International Paralympic Committee. Wheelchair Basketball could lose Tokyo 2020 spot

597 [Internet]. 2020 [cited 2020 Jun 10]. Available from:

598 https://www.paralympic.org/news/wheelchair-basketball-could-lose-tokyo-2020-spot

599 11. Moher D, Liberati A, Tetzlaff J, Altman DG, Group TP. Preferred reporting items for 600 systematic reviews and meta-analyses: The PRISMA statement. PLoS Med.

$601 \quad 2009 ; 6: \mathrm{e} 1000097$.

602 12. Downes MJ, Brennan ML, Williams HC, Dean RS. Development of a critical appraisal 603 tool to assess the quality of cross-sectional studies (AXIS). BMJ Open. 2016;6:e011458.

604 13. Balshem H, Helfand M, Schünemann HJ, Oxman AD, Kunz R, Brozek J, et al. GRADE 605 guidelines: 3. Rating the quality of evidence. J Clin Epidemiol. Pergamon; 2011;64:401-6.

606 14. Guyatt GH, Oxman AD, Kunz R, Brozek J, Alonso-Coello P, Rind D, et al. GRADE 607 guidelines 6. Rating the quality of evidence-imprecision. J Clin Epidemiol. 2011;64:128360893.

609 15. Guyatt GH, Oxman AD, Kunz R, Woodcock J, Brozek J, Helfand M, et al. GRADE 610 guidelines: 8. Rating the quality of evidence_-indirectness. J Clin Epidemiol. 2011;64:130361110.

612 16. Guyatt GH, Oxman AD, Kunz R, Woodcock J, Brozek J, Helfand M, et al. GRADE

613 guidelines: 7. Rating the quality of evidence-inconsistency. J Clin Epidemiol. 
615 17. Guyatt GH, Oxman AD, Montori V, Vist G, Kunz R, Brozek J, et al. GRADE guidelines:

616 5. Rating the quality of evidence — publication bias. J Clin Epidemiol. 2011;64:1277-82.

617 18. Guyatt GH, Oxman AD, Vist G, Kunz R, Brozek J, Alonso-Coello P, et al. GRADE

618 guidelines: 4. Rating the quality of evidence — study limitations (risk of bias). J Clin

619 Epidemiol. 2011;64:407-15.

620 19. Altmann VC, Groen BE, Hart AL, Vanlandewijck YC, Keijsers NLW. Classifying trunk 621 strength impairment according to the activity limitation caused in wheelchair rugby 622 performance. Scand J Med Sci Sports. 2018;28:649-57.

20. Altmann VC, Groen BE, Groenen KH, Vanlandewijck YC, van Limbeek J, Keijsers NL.

624 Construct validity of the trunk impairment classification system in relation to objective 625 measures of trunk impairment. Arch Phys Med Rehabil. 2016;97:437-44. strength test battery to permit evidence-based Paralympic classification. Medicine (Baltimore). 2014;93:e31.

22. Connick MJ, Beckman E, Vanlandewijck Y, Malone LA, Blomqvist S, Tweedy SM.

630 Cluster analysis of novel isometric strength measures produces a valid and evidence-based 631 classification structure for wheelchair track racing. Br J Sports Med. 2018;52:1123-9.

632 23. Gagnon C, Lessard I, Brais B, Côté I, Lavoie C, Synofzik M, et al. Validity and reliability 633 of outcome measures assessing dexterity, coordination, and upper limb strength in autosomal 634 recessive spastic ataxia of Charlevoix-Saguenay. Arch Phys Med Rehabil. 2018;99:1747-54. 
636 strength tests for evidence-based classification in Para swimming. J Sports Sci. 2019;37:40463713.

638 25. Hyde A, Hogarth L, Sayers M, Beckman E, Connick MJ, Tweedy S, et al. The impact of 639 an assistive pole, seat configuration, and strength in Paralympic seated throwing. Int J Sports 640 Physiol Perform. 2017;12:977-83.

641 26. Rosso V, Gastaldi L, Rapp W, Lindinger S, Vanlandewijck Y, Ayramo S, et al. Balance 642 perturbations as a measurement tool for trunk impairment in cross-country sit skiing. Adapt 643 Phys Aactivity Q. 2019;36:61-76.

644 27. Santos PBR, Vigário PS, Mainenti MRM, Ferreira AS, Lemos T. Seated limits-of645 stability of athletes with disabilities with regard to competitive levels and sport classification. 646 Scand J Med Sci Sports. 2017;27:2019-26.

647 28. Vanlandewijck YC, Verellen J, Beckman E, Connick M, Tweedy SM. Trunk strength 648 effect on track wheelchair start: Implications for classification. Med Sci Sports Exerc. $649 \quad 2011 ; 43: 2344-51$.

650 29. Artilheiro MC, Corrêa JCF, Cimolin V, Lima MO, Galli M, de Godoy W, et al. Three651 dimensional analysis of performance of an upper limb functional task among adults with 652 dyskinetic cerebral palsy. Gait Posture. 2014;39:875-81. 30. Bui HT, Audet O, Mathieu J, Gagnon C, Leone M. Computer-based assessment of upper654 limb incoordination in autosomal recessive spastic ataxia of Charlevoix-Saguenay patients: A 655 pilot study. J Neurol Sci. 2017;380:68-73.

657 coordination for Paralympic classification: Normative values and test-retest reliability. Sport 658 Eng. 2016;19:147-54. 
660 three measures of upper limb function in Friedreich ataxia. J Neurol. 2010;257:518-23.

33. Deuble RL, Connick MJ, Beckman EM, Abernethy B, Tweedy SM. Using Fitts' Law to detect intentional misrepresentation. J Mot Behav. 2016;48:164-71.

34. Gagnon C, Mathieu J, Desrosiers J. Standardized finger-nose test validity for coordination assessment in an ataxic disorder. Can J Neurol Sci. 2004;31:484-9. participation: A quantitative descriptive study in adults with autosomal recessive spastic ataxia of Charlevoix-Saguenay. Orphanet J Rare Dis. 2018;13:165. motor coordination impairment in Para swimmers with brain injury. J Sci Med Sport.

670 2019;22:526-31.

37. Roldan A, Sabido R, Barbado D, Caballero C, Reina R. Manual dexterity and intralimb coordination assessment to distinguish different levels of impairment in boccia players with cerebral palsy. Front Neurol. 2017;8:582.

38. Bjerkefors A, Rosén JS, Tarassova O, Arndt A. Three-dimensional kinematics and power output in elite Para-kayakers and elite able-bodied flat-water kayakers. J Appl Biomech. 2019;35:93-100. Act. 2013;6:17-29. 
681 Establishing the reliability of a novel battery of range of motion tests to enable evidence-

682 based classification in Para Swimming. Phys Ther Sport. 2018;32:34-41.

683 41. Reina R, Dominguez-Diez M, Urban T, Roldan A. Throwing distance constraints

684 regarding kinematics and accuracy in high-level boccia players. Sci Sports. 2018;33:299685306.

686 42. Connick MJ, Beckman E, Tweedy SM. Evolution and Development of Best Practice in 687 Paralympic Classification. In: Brittain I, Beacom A, editors. Palgrave Handb Paralympic 688 Stud. London: Palgrave Macmillan UK; 2018. p. 389-416.

689 43. Fitts PM. The information capacity of the human motor system in controlling movement 690 amplitude. J Exp Psychol. 1954;47:381-91.

691

692 
$693 \quad$ Figure captions

694 Figure 1: Flow diagram of studies through the eligibility screening process. 
Records identified through database searching $(n=3595)$
Additional records identified through other sources

$$
(n=26)
$$

\section{Records after duplicates removed}

$$
(n=2916)
$$

Records screened

$(n=2916)$
Records excluded $(n=2769)$

Full-text articles excluded, with reasons

$$
(n=124)
$$

-Did not study assessment of upper body function $(n=64)$.

-Participants not $15-55$ years $(n=32)$.

-Study in non-disabled and not designed to inform Paralympic classification $(n=7)$.

-Review article $(n=7)$.

-Full text not available $(n=5)$.

-Did not study an eligible impairment type $(n=4)$. - Conference proceeding $(n=2)$.

-Article not in English $(n=1)$.

-Insufficient reporting in methods $(n=1)$.

-Methods do not meet needs of evidence-based classification $(n=1)$. 
Table 1: Data extracted from the eligible studies regarding strength impairment.

\begin{tabular}{|c|c|c|c|c|c|c|}
\hline Authors & Objective & Sample size & Population & Assessment tool & Outcome measures & Results \\
\hline \multicolumn{7}{|c|}{ Para sport studies } \\
\hline $\begin{array}{l}\text { Altmann et al. } \\
2016\end{array}$ & $\begin{array}{l}\text { To assess validity } \\
\text { of Trunk } \\
\text { Impairment } \\
\text { Classification } \\
\text { system in } \\
\text { wheelchair rugby. }\end{array}$ & $\begin{array}{l}\mathrm{N}=34(\mathrm{sex} \\
\text { unspecified, } \\
18-59 \text { years })\end{array}$ & $\begin{array}{l}1+\text { year } \\
\text { experience in } \\
\text { wheelchair } \\
\text { basketball or } \\
\text { wheelchair rugby, } \\
\text { playing at } \\
\text { national or } \\
\text { international } \\
\text { level. }\end{array}$ & $\begin{array}{l}\text { Static balance: } \\
\text { Sat on a chair, placed on force platform. } \\
\text { Instructed to sit as still as possible for } 30 \\
\mathrm{~s} \text { on i) stable surface ( } 5 \mathrm{~cm} \text { foam } \\
\text { cushion) and ii) unstable surface } \\
\text { (inflated cushion so buttocks } 2 \mathrm{~cm} \\
\text { raised). } \\
\text { Dynamic balance: } \\
\text { In same position as static balance and } \\
\text { sitting on foam cushion. Maximal trunk } \\
\text { inclination posterior-anterior; left-right } \\
\text { lateral, } 90^{\circ} \text { from sagittal plane; right } \\
\text { forward-left backward and left forward- } \\
\text { right backward, } 45^{\circ} \text { from sagittal plane. } \\
\text { Isometric trunk strength: on plinth in } \\
\text { harness attached to load cell. Tested } \\
\text { forward, left and right. }\end{array}$ & $\begin{array}{l}\text { Static balance: } \\
\text { Sway area in } \mathrm{mm}^{2} \text {. Defined as the } \\
\text { ellipse around the total area of the } \\
\text { recorded centre of pressure during } \\
\text { the } 30 \mathrm{~s} \text { trial, containing } 95 \% \text { of } \\
\text { the sampled positions. } \\
\text { Dynamic balance: } \\
\text { Excursion of the centre of } \\
\text { pressure displacement in mm. } \\
\text { Pressure coordinates used to } \\
\text { calculate maximum and minimum } \\
\text { centre of pressure with excursion } \\
\text { the difference between the two. } \\
\text { Isometric strength: } \\
\text { Force in Newtons. }\end{array}$ & $\begin{array}{l}\text { Static balance: } \\
\text { No main effect of Trunk Impairment } \\
\text { Classification on sway area in } \mathrm{i}) \text { stable ( } \mathrm{p}= \\
0.528 \text { ) or ii) unstable conditions ( } \mathrm{p}= \\
0.236) \text {. } \\
\text { Dynamic balance: } \\
\text { Main effect of Trunk Impairment } \\
\text { Classification on left forward-right } \\
\text { backwards excursion ( } \mathrm{p}=0.12) \text {. Larger } \\
\text { excursion in } 1.5 \text { compared with } 0.5 \text { and } \\
1.0 \text {. } \\
\text { Isometric strength: } \\
\text { Main effect of classification in all } \\
\text { directions ( } \mathrm{p}<0.001) \text {. Left lateral strength } \\
\text { greater in } 1.0 \text { and } 1.5 \text { then } 0 . \text { Right and } \\
\text { forward strength greater in } 0.5,1.0 \text { and } 1.5 \\
\text { compared to } 0 .\end{array}$ \\
\hline $\begin{array}{l}\text { Altmann et al. } \\
2018\end{array}$ & $\begin{array}{l}\text { Assess } \\
\text { relationship } \\
\text { between trunk } \\
\text { strength and } \\
\text { activity limitation } \\
\text { in wheelchair } \\
\text { rugby. }\end{array}$ & $\begin{array}{l}\mathrm{N}=27(\text { all } \\
\text { male, } 37.4 \pm \\
10.2 \text { years })\end{array}$ & $\begin{array}{l}1+\text { year } \\
\text { experience in } \\
\text { wheelchair } \\
\text { basketball or } \\
\text { wheelchair rugby, } \\
\text { playing at } \\
\text { national or } \\
\text { international } \\
\text { level. }\end{array}$ & $\begin{array}{l}\text { IMPAIRMENT: } \\
\text { Isometric trunk strength: } \\
\text { On plinth in harness attached to load } \\
\text { cell. Tested forward, left and right. } \\
\text { ACTIVITY LIMITATION: } \\
\text { Tilt test: } \\
1 \text { rear wheel fixed to ground, aim to lift } \\
\text { other rear wheel off ground as much as } \\
\text { possible. } \\
\text { Acceleration: } \\
\text { Maximally accelerate from standstill. } \\
\text { Time recorded to push } 1 \text { m. } \\
\text { Sprint momentum: } \\
\text { Using the results of the acceleration test, } \\
\text { calculate the impulse with which an } \\
\text { athlete can hit an opponent. }\end{array}$ & $\begin{array}{l}\text { Isometric trunk strength: } \\
\text { Force in Newtons. } \\
\text { Tilt test: } \\
\text { Difference in initial (H0) and } \\
\text { maximal (H1) height reached, in } \\
\text { mm. } \\
\text { Acceleration: } \\
\text { Time in seconds. } \\
\text { Sprint momentum: } \\
\text { Body mass multiplied by the } \\
\text { average velocity over the first } 2 \mathrm{~m} \\
\left(\mathrm{~kg} \cdot \mathrm{m} \cdot \mathrm{s}^{-1}\right) \text {. }\end{array}$ & $\begin{array}{l}\text { Lateral trunk strength and tilt test: } \\
\mathrm{r}=0.50, \mathrm{p}=0.007 \text { between mean } \mathrm{L} / \mathrm{R} \\
\text { force and mean } \mathrm{L} / \mathrm{R} \text { tilt. } \\
\text { Significant increase in tilt height from } \\
\text { Cluster } 1 \text { to } 2 \text { and } 3 \text {. No difference } \\
\text { between Cluster } 2 \text { and } 3 \text {. } \\
\text { Forward trunk strength and acceleration: } \\
\mathrm{r}=0.59, \mathrm{p}=0.001 \text { between forward trunk } \\
\text { force and } 1 \text { m acceleration. } \\
\text { Forward trunk strength and sprint } \\
\text { momentum: } \\
\mathrm{r}=0.79, \mathrm{p}=0.0001 \text { between forward trunk } \\
\text { force and sprint momentum. } \\
\text { Differences between Clusters: } 1<3,4 ; 2< \\
3 \text {. }\end{array}$ \\
\hline $\begin{array}{l}\text { Beckman et al. } \\
2014\end{array}$ & $\begin{array}{l}\text { i) to establish } \\
\text { normative }\end{array}$ & $\begin{array}{l}\mathrm{N}=118(63 \\
\text { males, } 55\end{array}$ & $\begin{array}{l}\text { Regularly active, } \\
\text { non-disabled }\end{array}$ & $\begin{array}{l}\text { Isometric strength: } \\
\text { Grip strength was assessed using a }\end{array}$ & $\begin{array}{l}\text { Grip strength was measured in } \mathrm{kg} \\
\text { and converted to Newtons. }\end{array}$ & $\begin{array}{l}\text { Males were significantly stronger than } \\
\text { females in all measures. }\end{array}$ \\
\hline
\end{tabular}


pants, i1) to

evaluate the

reliability of

isometric

performance, iii)

to assess the

relationship

between strength

and body mass.

testing was valid

for classifying

wheelchair racing

athletes.

$\mathrm{N}=32$ (all male; $32.2 \pm$ 9.0 years).

$=14)$.
International level IMPAIRMENT:

wheelchair racing Isometric strength:

athletes $(\mathrm{T} 51, \mathrm{n}=\quad$ Using a load cell. Participants were

$5 ; \mathrm{T} 52, \mathrm{n}=6 ; \quad$ seated in the testing rig with legs and

$\mathrm{T} 53, \mathrm{n}=7 ; \mathrm{T} 54, \mathrm{n} \quad$ pelvis strapped.

\section{i) Para-swimmers}

who had a

national or

international

classification and i) Arm extension with $90^{\circ}$ shoulder abduction, $45^{\circ}$ horizontal shoulder flexion and $120^{\circ}$ elbow extension.

ii) Arm extension and trunk flexion with $30^{\circ}$ trunk flexion and the same arm position as previously used.

iii) Isolated trunk strength with $45^{\circ}$ trunk flexion.

iv) Combined pronation and grip strength with elbow at $90^{\circ}$ flexion and shoulder neutral in sagittal plane.

\section{PERFORMANCE}

Top speed:

From a maximal $15 \mathrm{~m}$ sprint from stationary position; and an absolute top speed in the finishing straight after accelerating from $150 \mathrm{~m}$ from the finish line.

Isometric force was measured in Newtons.

Isometric strength:

Force measured in Newtons.

Top speed:

Measured in $\mathrm{m} \cdot \mathrm{s}^{-1}$.

\section{IMPAIRMENT}

Isometric strength:

Using load cell. Participants were seated

with hip, knee and ankle at $90^{\circ}$ and

trunk strapped. Tests were performed on
Isometric strength:

Force measured in Newtons.

Maximal swim speed:
Speed measured in $\mathrm{m} \cdot \mathrm{s}^{-1}$
There was no significant difference between dominant and non-dominant sides.

ICCs for test-retest reliability ranged from 0.71-0.95; absolute difference ranged from 3.7-51.0 N (0.2-7.3\%); standard error of measurement ranged from 18.1-117.4 N.

For males all measures significantly correlated with body mass $(r=0.43-0.51)$. In females only grip strength significantly correlated with body mass $(r=0.33)$.

Significant correlation between all strength measures and $0-15 \mathrm{~m}$ top speed $(\mathrm{r}=0.54-$ $0.83)$ and absolute top speed $(r=0.61$ 0.88 ). Weakest correlation was with isolated trunk strength, and strongest correlation was for the dominant arm extension.

Cluster analysis produced 4 clusters. Significant difference in all strength measures between adjacent clusters, except for isolated trunk strength which only differed between Cluster 4 and other clusters.

Top speed (absolute and 10-15 m) were significantly different between Clusters 1 and 2, and Clusters 2 and 3. Absolute top speed was significantly faster in Cluster 4 versus 3 .

Validity:

Non-disabled males were significantly stronger than male Para-swimmers for shoulder flexion and extension on both limbs. 
years; 6

ere undertaking

planned training

female, $19.8 \pm$

4.1 years).

Impaired

muscle power:

$\mathrm{n}=19$ (9

male, $31.5 \pm$

7.7 years; 10

female, $29.9 \pm$

10.2 years)

Non-disabled:

$\mathrm{n}=30$ (15

male, $23.5 \pm$

4.1 years; 15

female, $23.3 \pm$

4.5 years). regimes and

competing at a

national or

level.

ii) Non-disabled

participants who

were healthy and

recreationally

active. international

both limbs.

Shoulder extension with the wrist at shoulder height, in $90^{\circ}$ shoulder flexion and neutral elbow, palm facing downwards.

Shoulder flexion with the palm facing forwards, elbow and shoulder in a neutral position.

\section{PERFORMANCE (Para-swimmers only)}

Maximal swim speed:

Using the freestyle stroke, participants accelerated to maximal speed,

maintained it for a $10 \mathrm{~m}$ period between 2 video cameras.
Hyde et al.
To examine how assistive pole and strength impacted seated throwing performance.
$\mathrm{N}=10(8$

male, 2

females; $32 \pm$

10 years).
Athletes with spinal cord injury (C6-L1). All participants were eligible for classification in Paralympic seated throwing, but participated in either seated throwing,

wheelchair basketball or wheelchair rugby.
Isometric strength test:

Grip strength using a handheld

dynamometer on both limbs with a neutral shoulder and $90^{\circ}$ elbow flexion.

Upper limb strength using a load cell: Throwing-arm push test performed in a chair with hips and knees at $90^{\circ}$ and strapped; $90^{\circ}$ shoulder flexion, $45^{\circ}$ horizontal shoulder flexion and $120^{\circ}$ elbow extension.

Push/pull synergy test performed in the same position, but without the strapping and non-dominant hand gripping the assistive pole.

Trunk flexion performed at $45^{\circ}$ trunk flexion and $120^{\circ}$ elbow extension.

The participant's sit-ski was fixed to a movable plate $(0.94 \times 0.84 \mathrm{~m})$ positioned on $1.4 \mathrm{~m}$ long parallel tracks.

Non-disabled females were significantly stronger than female Para-swimmers for all strength measures other than shoulder flexion on the non-dominant side.

Random forest algorithm successfully classified 25/26 male and 15/16 female Para-swimmers.

For the entire cohort of Para-swimmers, shoulder extension for dominant $(\mathrm{r}=0.53$, $\mathrm{p}<0.01)$ and non-dominant $(\mathrm{r}=0.47, \mathrm{p}<$ $0.01)$ and shoulder flexion for dominant $(\mathrm{r}$ $=0.38, \mathrm{p}<0.05)$ limbs significantly correlated with maximal swim speed. Nondominant shoulder flexion $(\mathrm{r}=0.15, \mathrm{p}=$ 0.35 ) did not significantly correlate with maximal swim speed.

Reliability (non-disabled only): ICC ranged from 0.94-0.97, coefficient of variation from $6.8-8.5 \%$ and standard error of measurement from 8.6-12.9 $\mathrm{N}$ for all strength measures.

Grip strength was measured in $\mathrm{kg}$.

Upper limb and trunk strength were measured in Newtons.

Grip strength $(r=0.59-0.77)$ and push/pull synergy $(\mathrm{r}=0.81 \& 0.84)$ significantly correlated with hand release speed during throwing with and without the assistive pole.

Correlation between hand release speed with throwing arm push $(\mathrm{r}=0.01 \& 0.31)$ and trunk flexion $(\mathrm{r}=0.50 \& 0.58)$ strength were not significantly correlated.

Temporal variables:

i) delay between onset of sledge k-mean cluster analysis divided athletes into 2 clusters: high and low impact of 
Participants sat in their sit-ski with strapping as used for a competition and were exposed to 12 unpredictable perturbations ( 6 forward, 6 backward; maximum acceleration $2.5 \mathrm{~m} \cdot \mathrm{s}^{-2}$; maximum velocity $0.5 \mathrm{~m} \cdot \mathrm{s}^{-1}$ ) with random intervals in between.

Participants were instructed to keep upper limbs in a neutral position and maintain trunk stability as much as possible.

Motion analysis system captured trunk angle as the angle between the vertical line from the hip marker and the line between the hip and acromion markers.
Santos et al. 2017
To investigate if playing experience and wheelchair rugby classification impact on trunk stability.
$\mathrm{N}=28$ (all male)

International level: $\mathrm{n}=19$, $29 \pm 4$ years.

National level: $\mathrm{n}=9,34 \pm 6$

years.
Wheelchair rugby players competing at either a national or international level within the past year.
Participants sat on a force platform (100 $\mathrm{Hz}$ ) mounted on a wooden block with feet unsupported and $75 \%$ of thigh length (greater trochanter to lateral epicondyle of femur) in contact with the platform.

Computer screen (1024 x 768 pixels) 1.2 $\mathrm{m}$ in front of the participant displayed the direction participants were required to lean as far as possible and then return to the starting position. There were 8 directions separated by $45^{\circ}$ and participants performed each lean three times continuously at a self-selected speed.

\section{acceleration.} association between trunk strength and

$\mathrm{N}=13(10$ male, 3

female; $26 \pm 7$ years).
International level IMPAIRMENT:

wheelchair racing Isometric strength:

track athletes.

sometric strength positioned at shoulder height in front of the sternum,

participants were assessed for maximal ii) delay between onset of acromion marker acceleration an trunk inverting of the movement.

Kinematic variables:

Trunk angle in degrees at i) rest before the stimulus, ii) $150 \mathrm{~ms}$ after the onset of acromion marker acceleration and iii) when the trunk inverted the movement.

Range of motion in degrees was calculated between i) and ii), and i) and iii).

Centre of pressure coordinates were calculated from the force platform for each trial and converted to a radial distance's time series.

Maximum amplitude in radial distance time series and associated centre of pressure coordinates were calculated. Maximum centre of pressure coordinates were used to adjust a $68 \%$ confidence ellipse, of which the area was calculated.

Base of support was calculated as the product of $75 \%$ thigh length and distance between right and left greater trochanters.

Limits of stability were then calculated as the centre of pressure ellipse area as a percentage of the base of support, which were then log transformed.

Delay in onset of the trunk inverting the movement was significantly longer for those with high impact of impairment for forward $(\mathrm{p}=0.003)$ and backward $(\mathrm{p}=$ 0.01 ) perturbations. There was no difference between clusters for onset of acromion marker acceleration.

The cluster with high impact of impairment had greater trunk extension at rest $(p=0.006)$ and trunk range of motion at the point of the trunk inverting the movement $(p=0.004)$ compared to the cluster with low impact of impairment.

There was no significant difference $(\mathrm{p}=$ 0.744 ) in the limits of stability between national and international level players.

Limits of stability were significantly greater $(p=0.035)$ in high versus low point players, but could not distinguish between low and mid point $(\mathrm{p}=0.194)$ or mid and high point $(\mathrm{p}=0.505)$ players.

Isometric strength:

Force measured in Newtons.

Relative trunk strength was calculated as the ratio of trunk
Relative trunk strength was significantly greater in participants with full trunk function $(\mathrm{p}=0.02)$ compared to those with partial trunk function. Maximum arm and trunk force were not significantly different 
arm and trunk strength. Pelvis, and thigh straps were used for both tests as well as a trunk strap for the arm test.

Arm isometric strength with the fingers on the inside of the load cell, elbows at $60^{\circ}$ flexion in the sagittal plane, with humeri internally rotated and forearms pronated. The trunk was supported against a backrest.

Trunk strength was assessed in $30^{\circ}$ trunk flexion with the arms in the same position as for the arm test.

\section{PERFORMANCE:}

Wheelchair acceleration:

Performed on a track in the participant's own chair using a Cheetah LMT system. Participants performed three, maximal

$15 \mathrm{~m}$ sprints.

Performed on an ergometer (radius 0.09 m) against a resistance equal to 4 times that off the track, calculated from a coast down trial on the track.

\section{Non-Para sport studies}

\begin{tabular}{lllll}
\hline Gagnon et al. & To examine & $\mathrm{N}=33(15$ & Patients & Grip strength: \\
2018 & validity and & male, 18 & confirmed with & Using a handheld dynamometer and \\
reliability of & female; $40.0 \pm$ & autosomal & both limbs. \\
& measures of & 11.0 years $).$ & recessive spastic & \\
coordination and & & ataxia of & \\
strength in spastic & & Charlevoix- & \\
ataxia. & & Saguenay.
\end{tabular}

Saguenay.
Wheelchair acceleration:

There was no significant difference in the

Distance $(\mathrm{m})$ covered at 1,2 and 3 either the track or ergometer between those with full trunk function and those with partial trunk function.

Correlation between trunk strength and acceleration on the track was low $(\mathrm{r}=$ 0.27-0.32) and nonsignificant.

\section{Inter-rater reliability:}

ICC was 0.97 and 0.98 , and standard error of measurement 1.6 and $1.3 \mathrm{~kg}$, for right and left limb, respectively.

\section{Validity:}

Males were significantly stronger than females $(\mathrm{p}<0.001)$

Grip strength could not discriminate between disease stage $(p>0.629)$ or age group $(\mathrm{p}>0.123)$ 
Table 2: Data extracted from the eligible studies regarding coordination impairment.

\begin{tabular}{|c|c|c|c|c|c|c|}
\hline Authors & Objective & Sample size & Population & Assessment tool & Outcome measures & Results \\
\hline \multicolumn{7}{|c|}{ Para sport studies } \\
\hline $\begin{array}{l}\text { Connick et al. } \\
2016\end{array}$ & $\begin{array}{l}\text { To develop } \\
\text { normative values } \\
\text { and test-retest } \\
\text { reliability of } \\
\text { measures of } \\
\text { coordination. }\end{array}$ & $\begin{array}{l}\mathrm{N}=20(10 \\
\text { male, } 10 \\
\text { female; } 20 \pm 1 \\
\text { years })\end{array}$ & $\begin{array}{l}\text { Non-disabled } \\
\text { individuals who } \\
\text { regularly } \\
\text { participated in } \\
\text { sport or physical } \\
\text { activity at least } 3 \\
\text { times a week. }\end{array}$ & $\begin{array}{l}\text { Musclelab data synchronisation unit } \\
\text { with four printed circuit boards were } \\
\text { used. Participants wore conductive } \\
\text { copper tape on the palmar surface of the } \\
\text { index finger to carry out the tasks. Each } \\
\text { was performed for } 15 \mathrm{~s} \text {. } \\
\text { Reciprocal tapping tasks (Wheelchair } \\
\text { specific): } \\
\text { i) unilateral with } 0.05 \mathrm{~m} \text { target, circuit } \\
\text { boards placed } 0.303 \mathrm{~m} \text { apart; ii) } \\
\text { unilateral with } 0.12 \mathrm{~m} \text { target, circuit } \\
\text { boards next to each other; iii) bilateral } \\
\text { tapping with } 0.12 \mathrm{~m} \text { target, boards } \\
\text { placed next to each other; iv) bilateral } \\
\text { pronation and supination with } 0.12 \mathrm{~m} \\
\text { target and } 0.07 \mathrm{~m} \text { vertical distance } \\
\text { between circuit boards. } \\
\text { Discrete tapping tasks (Throwing } \\
\text { specific): } \\
\text { Horizontal and vertical tapping with } \\
0.05 \text { and } 0.12 \mathrm{~m} \text { targets. Distance } \\
\text { between circuit boards was } 0.303 \mathrm{~m} \text {. }\end{array}$ & $\begin{array}{l}\text { For each task the mean movement } \\
\text { time was calculated in seconds. }\end{array}$ & $\begin{array}{l}\text { Reciprocal tasks: } \\
\text { Participants were significantly faster ( } \mathrm{p}= \\
0.003) \text { in the second visit for the unilateral } \\
\text { task with } 0.05 \mathrm{~m} \text { target on the dominant } \\
\text { side. } \\
\text { ICC from repeat visits ranged from } 0.54- \\
0.93 \text {. Lowest ICC was for unilateral task } \\
\text { with } 0.05 \mathrm{~m} \text { target }(0.54) \text { on the non- } \\
\text { dominant side, for all other tasks ICC was } \\
\text { greater than } 0.74 \text {. } \\
\text { Standard error of measurement ranged } \\
\text { from } 0.006-0.021 \mathrm{~s} \text {. } \\
\text { Discrete tasks: } \\
\text { ICC ranged from } 0.85-0.92 \text {. } \\
\text { Standard error of measurement ranged } \\
\text { from } 0.010-0.015 \mathrm{~s} \text {. }\end{array}$ \\
\hline $\begin{array}{l}\text { Deuble et al. } \\
2016\end{array}$ & $\begin{array}{l}\text { To investigate if } \\
\text { Fitts' Law could } \\
\text { detect } \\
\text { submaximal } \\
\text { performance } \\
\text { during tapping } \\
\text { tasks. }\end{array}$ & $\begin{array}{l}\mathrm{N}=10(5 \\
\text { male, } 5 \\
\text { female; } 24 \pm 4 \\
\text { years }) .\end{array}$ & $\begin{array}{l}\text { Non-disabled } \\
\text { individuals who } \\
\text { regularly } \\
\text { participated in } \\
\text { sport or physical } \\
\text { activity at least } 3 \\
\text { times a week. }\end{array}$ & $\begin{array}{l}\text { Tapping tasks were performed using } \\
\text { pairs of custom-made } 17.5 \times 12 \mathrm{~cm} \\
\text { fiberglass printed circuit boards. One the } \\
\text { four pairs of boards the targets were } 2.5 \text {, } \\
5,7.5 \text { and } 10 \mathrm{~cm} \text { wide. Boards were } \\
\text { connected to a Musclelab unit sampling } \\
\text { at } 100 \mathrm{~Hz} \text {. } \\
\text { Participants sat on a stool at a } 72.5 \mathrm{~cm} \\
\text { high bench with feet on a } 7.5 \mathrm{~cm} \text { high } \\
\text { footrest. Participants completed } 14 \text { trials } \\
\text { in } 7 \text { different conditions on } 3 \text { occasions: } \\
\text { i) Index of difficulty (ID) }=3 ; 10 \mathrm{~cm} \\
\text { wide plate with } 40.1 \mathrm{~cm} \text { gap between. } \\
\text { ii) ID = 4.01; } 7.5 \mathrm{~cm} \text { wide plate with } \\
60.6 \mathrm{~cm} \text { gap. }\end{array}$ & $\begin{array}{l}\text { The number of taps in } 15 \mathrm{~s} \text { was } \\
\text { recorded for each trial. This was } \\
\text { then used to calculate the mean } \\
\text { movement time (s). } \\
\text { During each trial, for each } \\
\text { individual the } \mathrm{R}^{2} \text { was calculated } \\
\text { for the fastest mean movement } \\
\text { time of each of the } 7 \text { IDs, for both } \\
\text { maximal and submaximal efforts. } \\
\text { For the } 4 \text { equal IDs, the difference } \\
\text { between the fastest and slowest } \\
\text { mean movement time was } \\
\text { calculated for maximal and } \\
\text { submaximal trials. }\end{array}$ & $\begin{array}{l}\text { The } R^{2} \text { score was significantly greater in } \\
\text { maximal trials compared to submaximal } \\
\text { trials }(p<0.001) \text {. } \\
\text { The difference between fastest and slowest } \\
\text { mean movement time was significantly } \\
\text { greater in submaximal compared to } \\
\text { maximal trials ( } p=0.021) \text {. } \\
\text { In maximal trials there was no change in } \\
\text { the } R^{2} \text { value }(p=0.537) \text { or difference } \\
\text { between fastest and slowest times in the } \\
\text { four equal IDs }(p=0.767) \text { across repeat } \\
\text { trials. }\end{array}$ \\
\hline
\end{tabular}


iii) $\mathrm{ID}=4.6 ; 2.5 \mathrm{~cm}$ wide plate with

$30.4 \mathrm{~cm}$ gap.

iv) $\mathrm{ID}=3.6 \mathrm{a} ; 10 \mathrm{~cm}$ wide plate with

$60.6 \mathrm{~cm}$ gap.

v) $\mathrm{ID}=3.6 \mathrm{~b} ; 7.5 \mathrm{~cm}$ wide plate with

$45.4 \mathrm{~cm}$ gap.

vi) $\mathrm{ID}=3.6 \mathrm{c} ; 5 \mathrm{~cm}$ wide plate with 30.4

cm gap.

vii) $\mathrm{ID}=3.6 \mathrm{~d} ; 2.5 \mathrm{~cm}$ wide plate with

$15.2 \mathrm{~cm}$ gap.

Participants completed each task in a randomised order with maximal effort and then submaximal effort at least $20 \%$ slower.

\begin{tabular}{|c|c|c|c|}
\hline & $\begin{array}{l}\text { To examine } \\
\text { validity of } \\
\text { coordination tasks } \\
\text { in Para-swimmers } \\
\text { with brain injury. }\end{array}$ & $\begin{array}{l}\text { Para- } \\
\text { swimmers: } \mathrm{n}= \\
21 \text { ( } 16 \text { male, } \\
28 \pm 7 \text { years; } 5 \\
\text { female, } 20 . \pm \\
5 \text { years). }\end{array}$ & $\begin{array}{l}\text { i) Para-swimmers } \\
\text { who had a } \\
\text { national or } \\
\text { international } \\
\text { classification and } \\
\text { were undertaking } \\
\text { planned training } \\
\text { regimes and } \\
\text { competing at a } \\
\text { national or } \\
\text { international } \\
\text { level. }\end{array}$ \\
\hline
\end{tabular}

\section{IMPAIRMENT}

target. Pad centres were placed $0.195 \mathrm{~m}$ pads with right and left fingers as

\section{PERFORMANCE (Para-swimmers only)}

maintained it for a $10 \mathrm{~m}$ period between

Roldan et al. To design new 2017 sport-specific

tests of manual

dexterity and

intralimb

coordination in
$\mathrm{N}=73$ Boccia players with

cerebral palsy

(42 male, 31 female).
Boccia players classified as $\mathrm{BC} 1$ or $\mathrm{BC} 2$ competing in regional or national competitions.
Tapping tasks used custom-made

wireless pads with a $0.195 \times 0.10 \mathrm{~m}$ apart. Trials were $15 \mathrm{~s}$.

Bilateral tapping was performed with the arms extended and hand in a fist with index finger extended. Participants alternately tapped the target on the two quickly and accurately as possible.

Unilateral tapping with dominant and dominant hand was performed with the pads in the same position as for the bilateral task. Participants used one hand to alternate tapping between the two pads as quickly and accurately as possible. Maximal swim speed:

Using the freestyle stroke, participants accelerated to maximal speed, 2 video cameras.

Mean movement time was calculated in milliseconds.

Symmetry ratio was calculated between dominant and non-

dominant limb for the unilateral task.

Box and block test:

Participants have to transfer $2.54 \mathrm{~cm}^{3}$

blocks from one section of a box to

another. Participants used their throwing hand and performed two trials of $1 \mathrm{~min}$.

Box and block test: Number of blocks moved in 1

Box and ball test:
Validity:

Mean movement time was faster, and symmetry score greater in non-disabled compared to Para-swimmers.

Random forest algorithm correctly classified $96 \%$ of participants as nondisabled or Para-swimmer.

Dominant $(r=-0.72, p<0.01)$ and nondominant $(\mathrm{r}=-0.54, \mathrm{p}=0.01)$ unilateral tapping performance significantly correlated with maximal swim speed.

Bilateral tapping $(\mathrm{r}=-0.21, \mathrm{p}=0.37)$ and symmetry score $(r=-0.36, p=0.15)$ did not significantly correlate with maximal swim speed.

Reliability (non-disabled only): ICC was $0.85,0.91,0.85$ and 0.42 ; coefficient of variation 5.4, 4.2, 5.2 and $4.1 \%$; and standard error of the measurement 5, 8, $11 \mathrm{~N}$ and 0.04 for bilateral, dominant and non-dominant tapping and symmetry score, respectively. Large, significant $(\mathrm{r}=0.80, \mathrm{p}<0.001)$ correlation between the Box and block and Box and ball test.

Moderate to very large correlation ( $\mathrm{r}=$ 0.30 to $-0.75, \mathrm{p}<0.05)$ between discrete 
$\mathrm{BC} 1: \mathrm{n}=33$,

$34 \pm 16$ years;

$\mathrm{BC} 2: \mathrm{n}=40$,

$34 \pm 14$ years.

$\mathrm{N}=19$ non-

disabled

controls $(28 \pm$

7 years).

\section{Box and ball test:}

Same procedure as Box and block test

Adults witho

any physical

impairment.

\section{Tapping tasks:}

Using metal plates $30 \times 20 \mathrm{~cm}$ with target area of $18 \times 5 \mathrm{~cm}$. Participants crossed their non-throwing arm across their chest and arranged throwing hand into a fist with index finger extended.

Discrete horizontal: Wheelchair placed parallel to a table, $10 \mathrm{~cm}$ form the tapping plates. Participant's shoulder was aligned with the rear plate. Centre of the plates were $30 \mathrm{~cm}$ apart. On a verbal command, participants moved their index finger from the rear to forward plate as quickly as possible, to the target area. Participants completed 10 cycles.

Discrete vertical: Arranged in a "L" shape at $90^{\circ}$ with $30 \mathrm{~cm}$ between plate centres. Participants started with their finger on the horizontal plate and moved on the command to the vertical plate.

Discrete vertical with ball: Using 14 x 7 $\mathrm{cm}$ plates loaded on springs to register contact. Contact could be made anywhere on the plate. Replicated the other discrete vertical task but performed whilst holding a ball, rather than with their finger.

Reciprocal vertical tapping with ball: As with the discrete task, but participants continually tapped alternately between plates.
Discrete tapping tasks: Average time (s) to move between plates across 10 trials.

Reciprocal tapping task:

Number of successful contacts made in $1 \mathrm{~min}$.
The non-disabled control group performed significantly better than Boccia players on all tests.

There was significant differences between $\mathrm{BC} 1$ and $\mathrm{BC} 2$ Boccia players for i) Box and block, ii) Box and ball and iii)

reciprocal vertical tapping task with ball.

Intrasession reliability was excellent for the discrete $(\mathrm{ICC}=0.87)$ and reciprocal $(\mathrm{ICC}=0.88)$ tapping tasks using the ball.

\section{Non-Para sport studies}

\begin{tabular}{|c|c|c|c|c|c|c|}
\hline $\begin{array}{l}\text { Artilheiro et } \\
\text { al. } 2014\end{array}$ & $\begin{array}{l}\text { To analyse the } \\
\text { performance of } \\
\text { adults with } \\
\text { dyskinetic } \\
\text { cerebral palsy } \\
\text { during an upper }\end{array}$ & $\begin{array}{l}\mathrm{N}=16 \text { adults } \\
\text { with } \\
\text { dyskinetic } \\
\text { cerebral palsy } \\
(10 \text { males, } 6 \\
\text { females; } 30 \pm\end{array}$ & $\begin{array}{l}\text { Adults with } \\
\text { dyskinetic } \\
\text { cerebral palsy and } \\
\text { age-matched } \\
\text { controls. }\end{array}$ & $\begin{array}{l}\text { Coordination during upper limb } \\
\text { movement: } \\
\text { Sat on a chair with hips, knees and } \\
\text { ankles at } 90^{\circ} \text {. Task was to raise a mug } \\
(350 \mathrm{~g}) \text { from a position of } 75 \% \\
\text { maximum passive elbow extension, to }\end{array}$ & $\begin{array}{l}\text { Spatiotemporal variables: } \\
\text { Time (s) to execute lifting mug to } \\
\text { mouth; adjusting phase, returning } \\
\text { mug to initial position. } \\
\text { Ratio of lifting to returning. }\end{array}$ & $\begin{array}{l}\text { Spatiotemporal variables: } \\
\text { Execution of lifting, adjusting and } \\
\text { returning the mug was significantly slower } \\
(\mathrm{p}<0.05) \text { in adults with dyskinetic } \\
\text { cerebral palsy. The ratio between lifting } \\
\text { and returning was not different between }\end{array}$ \\
\hline
\end{tabular}


$\mathrm{N}=11$ agematched controls $(2$ males, 9

4 years) the mouth, adjust the movement and return it to the original position. This was repeated six times, consecutively, a a comfortable velocity and without releasing the mug between repetitions.

Bui et al. 2017

To investigate if a computer-based Archimedes spiral test can asses coordination performance.
$\mathrm{N}=49(25 \pm 7$ years); $\mathrm{n}=13$ patients with autosomal recessive spastic ataxia of CharlevoixSaguenay (29 \pm 9 years); $\mathrm{n}=$ 36 nondisabled $(24 \pm$ 6 years).
Patients with autosomal recessive spastic ataxia of CharlevoixSaguenay (ARSACS) and non-disabled controls.
Archimedes spiral test. This was performed on a $56 \mathrm{~cm}$ optical touch computer screen, using MATLAB sampling at $100 \mathrm{~Hz}$. The spiral was 15 $\mathrm{cm}$ wide and $15 \mathrm{~cm}$ tall, with $2.5 \mathrm{~cm}$ between each loop. Participants traced the spiral with the index finger of their preferred hand at a self-paced speed. Screen positioned at arm's length with slight elbow flexion.
Peak and mean velocity $\left(\mathrm{m} \cdot \mathrm{s}^{-1}\right)$

three upper limb female; $32 \pm$

function tests in 13 years).
Individuals with

Friedrich Ataxia.

9-hole peg test:

A timed measure of finger dexterity, where individuals have to place and remove nine pegs in a pegboard as quickly as possible. Both limbs are tested three times and the mean time calculated.

\section{Box and block test}

Jebsen Taylor hand function test: A test of arm and hand function representing everyday function. Participants must 1) write a short sentence; 2 ) turn over five $3 \times 5$ " cards; during movement, as well as time to peak velocity (s).

Smoothness of movement was assessed using i) the number of movement units, the number of velocity peaks over $10 \%$ of peak velocity; ii) mean index of curvature, ratio of trajectory of $3^{\text {rd }}$ finger to straight line connecting start and end of movement; iii) jerk, the rate of change in acceleration of the position.

Execution time:

Recorded in seconds, the total time to complete the spiral.

Spatial displacement:

Distance (in pixels) between the traced and reference spiral calculated at $100 \mathrm{~Hz}$. This is used the calculate the mean error and maximum error.

Smoothness of movement: Summation of frequency analysis from 0.1 to $2.9 \mathrm{~Hz}$ using fast

Fourier transform.

9-hole peg test:

Time in seconds averaged over the 3 repeat trials, for both limbs.

groups.

Peak and mean velocity were lower and time to reach peak velocity longer, in the group with dyskinetic cerebral palsy.

All measures of smoothness were significantly higher in the group with dyskinetic cerebral palsy.

No difference in execution time between groups $(\mathrm{p}=0.81)$.

Mean error $(\mathrm{p}=0.001, \mathrm{ES}=1.80)$ and maximum error $(\mathrm{p}=0.004, \mathrm{ES}=1.40)$ significantly greater in ARSACS patients.

Significant difference in smoothness of movement $(\mathrm{p}<0.002)$ between groups.

Logistic regression correctly classified people based on mean error $(95.9 \%)$ and maximum error $(89.8 \%)$.

Analysis considering frequency from 1.2 to $1.7 \mathrm{~Hz}$ correctly classified $100 \%$ of cases.

All test performances significantly negatively correlated with disease duration $(\mathrm{r}=-0.41$ to -0.54$)$ and Friedrich Ataxia Rating Scale ( $r=-0.73$ to -0.82 ).

Box and block test:

Number of blocks moved recorded as $1 \cdot \mathrm{min}^{-1}$.

Jebsen Taylor hand function test: Time recorded for both limbs.
Significant decrease in non-dominant limb 9-hole peg test $(\mathrm{p}=0.02)$ and box block test $(\mathrm{p}=0.01)$ at 12 month follow-up. No other test showed significant change over course of 12 months. 


$\begin{array}{llll}\text { Gagnon et al. } & \begin{array}{l}\text { To examine the } \\ \text { construct validity } \\ \text { of the }\end{array} & \begin{array}{l}\mathrm{N}=24(12 \\ \text { male, } 12\end{array} & \begin{array}{l}\text { Patients } \\ \text { female; } 37.5 \%\end{array} \\ \begin{array}{l}\text { Standardised } \\ \text { Finger to Nose }\end{array} & \begin{array}{l}\text { less than } 40 \\ \text { ARSACS. }\end{array} \\ \text { test with upper } \\ \text { extremity function } \\ \text { tests and to } \\ \text { examine the effect } \\ \text { of age on } \\ \text { performance. }\end{array}$

Gagnon et al. To examine the 2018 (Orphanet)

Gagnon et al. 2018

(Archives) effect of disease severity on dexterity and coordination in adults with ARSACS.
Participants were with no walking difficulty, ii) those who used a walking aid and iii) permanent wheelchair users.

Intra-rater group: validity and reliability of measures of coordination and strength in spastic ataxia.

Patients confirmed with $\mathrm{N}=42(21 \quad$ ARSACS. male, 21 female; $39 \pm$ 11 years).

\section{$\mathrm{N}=28(16$ \\ male, 12 \\ female; $38 \pm$ \\ Patients confirmed with ARSACS. \\ Purdue pegboard \\ 9-hole peg test}

13 years) split into i) those

pick up six small items and place

them in a container; 4) simulate feeding; 5) stack four checkers; 6) lift five large, empty cans; 7) lift five large, weighted cans. This is repeated using both limbs.

Standardised finger to nose test:

\section{Box and block test}

Inter-rater group: $\mathrm{N}=33(15$ male, 18 female; $40 \pm$ 11 years).
Using their index finger, participants must alternately touch the end of their nose and a horizontal target $45 \mathrm{~cm}$ away. This was performed using the preferred limb.

Purdue pegboard:

Used to measure unilateral and bilateral dexterity, participants have to place pins, washers and collars on a board in 30 or $60 \mathrm{~s}$.

Standardised finger to nose test

Standardised finger to nose test:

Performance recorded as the number of targets hit in $20 \mathrm{~s}$ and averaged over two trials.

\section{Box and block test:}

Number of blocks moved

recorded as $1 \cdot \mathrm{min}^{-1}$.

Purdue pegboard:

Recorded as the number of completed arrangements in 1 minute.

\section{Purdue pegboard:}

Recorded as the number of pegs places on the board in $30 \mathrm{~s}$.

9-hole peg test:

Time recorded in seconds and averaged over two trials for both limbs.

Standardised finger to nose test: Performance recorded as the number of targets hit in $20 \mathrm{~s}$ and averaged over two trials.

9-hole peg test:

Time recorded in seconds and averaged over two trials for both limbs.

Archimedes spiral test:

Participants drew a spiral over a printed Standardised finger to nose test: spiral without lifting the pen off the Performance recorded as the page. This was repeated twice.

Fast alternating hand movements: 10 cycles of alternate pronation and supination of the hand on their thigh, completed as quickly as possible and using both limbs.

number of targets hit in $20 \mathrm{~s}$ and averaged over two trials.

Archimedes spiral test:

Time take to draw spiral in of drawing: i) normative or
Standardised finger to nose test showed moderate-strong correlation with Box

block test and Purdue pegboard $(\mathrm{r}=0.82, \mathrm{p}$ $=0.01)$.

Performance on the Standardised finger to nose test was significantly greater in those younger than 40 years $(12.7 \pm 2.2)$ compared to older than 40 years $(6.7 \pm$ 3.4).

Performance in all tests was significantly greatest in those who could walk and worst in those who were wheelchair users.

Intra-rater reliability:

ICC for 9-hole peg test and standardised finger to nose test range from 0.93-0.97. Standard error of measurement was 6.5 and $7.1 \mathrm{~s}$ for right and left limbs for 9-hole peg test, and were 0.9 and 0.6 for the standardised finger to nose test. seconds combined with precision
Inter-rater reliability:

ICC for 9-hold peg test and standardised

finger to nose test ranged from 0.903 0.981 .

Validity: 
slightly irregular, $>1 \mathrm{~cm}$ traced outside line, $<30 \mathrm{~s}$; ii) slightly irregular, $>1 \mathrm{~cm}$ traced outside line, $>30 \mathrm{~s}$; iii) irregular, tracing

touches or crosses 2 lines or spiral unrecognised or incomplete.

Fast alternate hand movements: Time recorded in seconds. Mean of both limbs used to categorise

as i) normative or slightly

irregular, $<10 \mathrm{~s}$; ii) clearly

irregular but $<10 \mathrm{~s}$; iii) very

irregular, $>10 \mathrm{~s}$ or unable to

complete.
Males were significantly better performers than females at the 9-hole peg test $(\mathrm{p}<$ 0.037 ), but not standardised finger to nose test $(\mathrm{p}>0.161)$.

9-hole peg test and standardised finger to nose test were able to significantly ( $\mathrm{p}<$

0.001 ) discriminate participants according to their performance in Archimedes spiral and Fast alternate hand movements tests.

Both 9-hole peg test and finger to nose test could discriminate according to disease stage $(\mathrm{p}<0.001)$ and age $(\mathrm{p}<0.001)$. 
Table 3: Data extracted from the eligible studies regarding range of motion impairment.

\begin{tabular}{|c|c|c|c|c|c|c|}
\hline Authors & Objective & Sample size & Population & Assessment tool & Outcome measures & Results \\
\hline \multicolumn{7}{|c|}{ Para sport studies } \\
\hline $\begin{array}{l}\text { Bjerkefors et } \\
\text { al. } 2019\end{array}$ & $\begin{array}{l}\text { To examine } \\
\text { differences in } \\
\text { joint angles and } \\
\text { range of motion in } \\
\text { able-bodied and } \\
\text { para-kayak } \\
\text { athletes. }\end{array}$ & $\begin{array}{l}\mathrm{N}=51(34 \\
\text { male, } 17 \\
\text { female) } \\
\text { Para-kayak: } \mathrm{n} \\
=41 \text { ( } 28 \text { male, } \\
13 \text { female; } 35 \\
\pm 9 \text { years). } \\
\text { Able-bodied: } \\
\mathrm{n}=10 \text { (6 } \\
\text { male, } 4 \\
\text { female; } 20 \pm 1 \\
\text { years). }\end{array}$ & $\begin{array}{l}\text { Para-kayak } \\
\text { athletes } \\
\text { competing at } \\
\text { national or } \\
\text { international level } \\
\text { with over } 1 \text { year } \\
\text { experience. } \\
\text { Elite able-bodied } \\
\text { kayak athletes. }\end{array}$ & $\begin{array}{l}\text { Kinematic analysis of kayak } \\
\text { performance on a kayak ergometer } \\
\text { during } 20 \text { paddle cycles of the greatest } \\
\text { intensity that could be maintained for } \\
\text { the } 20 \text { cycles. If para-athletes used } \\
\text { adaptive seats or straps when competing } \\
\text { these were used on the ergometer also. } \\
\text { Kinematic data were collected } \\
\text { throughout the paddle cycle which was } \\
\text { defined as the time from catch to catch } \\
\text { for each side. }\end{array}$ & $\begin{array}{l}\text { Range of motion: } \\
\text { Shoulder: flexion-extension, } \\
\text { abduction-adduction, internal- } \\
\text { external rotation. } \\
\text { Elbow: flexion-extension. } \\
\text { Wrist: dorsal-palmar flexion, } \\
\text { ulnar-radial deviation. } \\
\text { Trunk: flexion-extension, } \\
\text { rotation. } \\
\text { Variables were recorded for } \\
\text { maximum and minimum angle } \\
\text { values and range of motion in } \\
\text { degree. }\end{array}$ & $\begin{array}{l}\text { Able-bodied athletes showed greater } \\
\text { maximal trunk flexion angle and trunk } \\
\text { rotation range of motion. The most } \\
\text { impaired Para-kayak athletes showed } \\
\text { greater trunk extension. } \\
\text { Able-bodied and the least impaired Para- } \\
\text { kayak athletes showed greater maximal } \\
\text { shoulder flexion, but more impaired Para- } \\
\text { kayak athletes had greater should } \\
\text { extension and range of motion. } \\
\text { Significant positive correlations were } \\
\text { found between maximum shoulder flexion, } \\
\text { maximum trunk flexion and trunk and } \\
\text { pelvis range of motion with power output } \\
\text { during paddling. }\end{array}$ \\
\hline $\begin{array}{l}\text { Fung et al. } \\
2013\end{array}$ & $\begin{array}{l}\text { To examine how } \\
\text { the supporting bar } \\
\text { on trunk function } \\
\text { during wheelchair } \\
\text { fencing. }\end{array}$ & $\begin{array}{l}\mathrm{N}=14(8 \\
\text { male, } 6 \\
\text { female; } 30 \pm 6 \\
\text { years }) .\end{array}$ & $\begin{array}{l}\text { Elite wheelchair } \\
\text { fencers competing } \\
\text { at the } \\
\text { international level } \\
(6.6 \pm 3.8 \text { years }) .\end{array}$ & $\begin{array}{l}\text { Digital video camcorder }(50 \mathrm{~Hz}) \\
\text { captured participants performing i) } \\
\text { lunge and ii) fast-return with and } \\
\text { without a supporting bar held by the } \\
\text { non-fencing arm. } \\
\text { Video camera was placed } 10 \mathrm{~m} \text { away } \\
\text { and calibrated using a } 1 \text { x } 1 \mathrm{~m} \\
\text { calibration board. }\end{array}$ & $\begin{array}{l}\text { Maximum trunk angle: calculated } \\
\text { as the angle between the line of } \\
\text { the shoulder and iliac crest of the } \\
\text { fencing arm with the vertical line } \\
\text { perpendicular to the ground } \\
\text { through the hip joint. }\end{array}$ & $\begin{array}{l}\text { Maximum trunk angle was significantly } \\
\text { greater in the lunge and fast-return with } \\
\text { the use of the supporting bar }(\mathrm{p}<0.05) \text {. } \\
\text { Without the supporting bar, maximal lunge } \\
\text { and fast-return trunk angle were } \\
\text { significantly different based on wheelchair } \\
\text { fencing classification. } \\
\text { There were no differences based on } \\
\text { wheelchair fencing classification with the } \\
\text { use of the supporting bar. }\end{array}$ \\
\hline $\begin{array}{l}\text { Hyde et al. } \\
2017\end{array}$ & $\begin{array}{l}\text { To examine how } \\
\text { assistive pole and } \\
\text { strength impacted } \\
\text { seated throwing } \\
\text { performance. }\end{array}$ & $\begin{array}{l}\mathrm{N}=10(8 \\
\text { male, } 2 \\
\text { females; } 32 \pm \\
10 \text { years })\end{array}$ & $\begin{array}{l}\text { Athletes with } \\
\text { spinal cord injury } \\
\text { (C6-L1). All } \\
\text { participants were } \\
\text { eligible for } \\
\text { classification in } \\
\text { Paralympic seated } \\
\text { throwing, but } \\
\text { participated in } \\
\text { either seated } \\
\text { throwing, }\end{array}$ & $\begin{array}{l}\text { Kinematic analysis of seated throwing } \\
\text { with and without an assistive pole in } \\
\text { both a standardised and self-selected } \\
\text { condition. The standardised position had } \\
\text { a seat angle of } 30^{\circ} \text { and backrest height } \\
\text { of } 18 \% \text { of athlete's sitting height. In the } \\
\text { self-selected condition these could be } \\
\text { individually altered by the participant. } \\
\text { Kinematic data were collected for start } \\
\text { of forward movement; cocking to throw; }\end{array}$ & $\begin{array}{l}\text { Range of motion was measured in } \\
\text { degrees. } \\
\text { Angular velocity was measured } \\
\text { in }{ }^{\circ} \cdot \mathrm{s}^{-1} \text {. }\end{array}$ & $\begin{array}{l}\text { Use of an assistive pole led to significantly } \\
\text { greater hand release speed, elbow flexion } \\
\text { at the start of the throw and shoulder } \\
\text { external rotation angular velocity during } \\
\text { cocking. } \\
\text { Seat configuration had no effect on any } \\
\text { kinematic variable. }\end{array}$ \\
\hline
\end{tabular}


Hypertonia: $\mathrm{n}$ $=11$ ( 9 male, 2 female; $27 \pm$ 6 years).

Non-disabled: $\mathrm{n}=42(20$

male, 22 female; $23 \pm 5$ active. years). arm-acceleration; and release phases and analysed for range of motion and angular velocity of elbow flexion, shoulder rotation, trunk rotation, trunk flexion. i) Para-swimmers Upper limb active range of motion was who had a national or international classification and were undertaking planned training regimes and competing at a

national or international level.

ii) Non-disabled participants who were healthy and recreationally assessed using a digital inclinometer and goniometer.

i) bilateral shoulder flexion, ii) shoulder abduction, iii) elbow flexion/extension were performed seated in a chair with feet flat on the ground.

v) shoulder internal/external rotation at $90^{\circ}$ shoulder abduction and elbow flexion were performed lying on their back.

vi) shoulder extension (with elbow flexed and extended), vii) shoulder abduction and viii) shoulder flexion were performed prone.

ix) trunk functional reach forwards, backwards, left and right were performed sat on a plinth with hips and knees at $90^{\circ}$, feet on a stool and arms crossed over chest.
Range of motion was measured in

degrees.

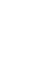

No significant difference in shoulder

flexion or abduction between disabled and non-disabled groups. Para-swimmers with impaired muscle power had significantly reduced $(\mathrm{p}<0.05)$ elbow flexion and extension compared to non-disabled.

Shoulder internal rotation was significantly reduced $(\mathrm{p}<0.01)$ in Para-swimmers with hypertonia, and shoulder internal and external rotation $(p<0.01)$ in Paraswimmers with impaired muscle power, compared to non-disabled.

Functional reach in all directions was significantly reduced $(\mathrm{p}<0.01)$ in Paraswimmers compared to non-disabled.

Intra-rater reliability (non-disabled only): For all measures, other than left arm elbow extension $(\mathrm{p}=0.04)$ there was no significant difference $(p>0.14)$ between repeat trials.

ICCs ranged from 0.68 to 0.96 , and standard error of measurement from 1.42 to 4.60 degrees.

Inter-rater reliability (non-disabled only): All measures, other than elbow flexion and shoulder internal rotation $(\mathrm{p}<0.01)$ left were not significantly different $(p>0.05)$ between raters.

ICCs ranged from 0.62 to 0.98 and standard error of measurement from 1.42 to 6.52 degrees.
Kinematic analysis of 10 throws in 4 middle distance $(5 \mathrm{~m})$, iii) long distance $(9 \mathrm{~m})$ and iv) maximum speed throw as conditions: i) short distance $(2 \mathrm{~m})$, ii)
Angles in degrees were calculated for elbow flexion, elbow extension and trunk inclination.
Elbow flexion and extension were significantly greater with each increment in throwing distance, and for maximum throwing speed $(\mathrm{p}<0.001)$.

\section{players \\ $\mathrm{N}=5$
years).}


Trunk inclination was significantly greater in medium versus short throw $(p=0.006)$; medium versus long $(p=0.002)$ and long versus maximum speed throw $(\mathrm{p}<0.05)$.

BC2 players had significantly greater elbow flexion, trunk inclination and ball release speed $(p<0.001)$ than $B C 1$ players.

There was a moderate positive correlation between elbow extension and ball release speed $(\mathrm{r}=0.525, \mathrm{p}<0.001)$.

\section{Non-Para sport studies}

Artilheiro et

al. 2014

To analyse the performance of

adults with

dyskinetic

cerebral palsy

during an upper

limb movemen

task.

\section{$\mathrm{N}=16$ adults \\ with \\ dyskinetic \\ Adults with \\ dyskinetic \\ cerebral palsy and \\ Range of motion during upper limb \\ movement: \\ Sat on a chair with hips, knees and}

cerebral palsy

(10 males, 6

females; $30 \pm$

4 years).

$\mathrm{N}=11$ age-

matched

controls $(2$

males, 9

females; $24 \pm$

4 years) age-matched

controls. ankles at $90^{\circ}$. Task was to raise a mug $(350 \mathrm{~g})$ from a position of $75 \%$

maximum passive elbow extension, to

the mouth, adjust the movement and

return it to the original position. This

was repeated six times, consecutively, at

a comfortable velocity and without

releasing the mug between repetitions.

Range of motion:
Shoulder: flexion-extension,
abduction-adduction, internal-
external rotation; elbow flexion-
extension; forearm pronation-
supination.
Measured variables were starting
position; minimum and maximum
angular values; and range of
motion in degrees.

motion in degrees.

\section{Range of motion:}

At the start position, the dyskinetic cerebral palsy group had decreased shoulder flexion and increased elbow flexion and forearm pronation.

Minimum angle for shoulder flexion was ower in dyskinetic cerebral palsy, but minimum angle for shoulder abduction, elbow flexion and forearm pronation.

Maximum angle of shoulder and elbow flexion were decreased in dyskinetic cerebral palsy, but forearm pronation was increased.

Range of motion for shoulder flexion, elbow flexion and forearm pronation were lower in dyskinetic cerebral palsy. 
Table 4: Quality assessment for each study using a modified appraisal tool for cross-sectional studies.

\begin{tabular}{|c|c|c|c|c|c|c|c|c|c|c|c|c|c|c|c|c|c|}
\hline Authors & 1 & 2 & 3 & 4 & 5 & 6 & 8 & 9 & 10 & 11 & 12 & 15 & 16 & 17 & 18 & 19 & 20 \\
\hline Altmann et al. 2016 & $\mathrm{Y}$ & $\mathrm{Y}$ & $\mathrm{N}$ & $\mathrm{Y}$ & $\mathrm{Y}$ & $\mathrm{Y}$ & $\mathrm{Y}$ & $\mathrm{Y}$ & $\mathrm{Y}$ & $\mathrm{Y}$ & $\mathrm{Y}$ & $\mathrm{Y}$ & $\mathrm{Y}$ & $\mathrm{Y}$ & $\mathrm{Y}$ & NR & $\mathrm{Y}$ \\
\hline Beckman et al. 2014 & $\mathrm{Y}$ & $\mathrm{Y}$ & $\mathrm{Y}$ & $\mathrm{Y}$ & $\mathrm{Y}$ & $\mathrm{Y}$ & $\mathrm{Y}$ & $\mathrm{Y}$ & $\mathrm{Y}$ & $\mathrm{Y}$ & $\mathrm{Y}$ & $\mathrm{Y}$ & $\mathrm{Y}$ & $\mathrm{Y}$ & $\mathrm{Y}$ & NR & $\mathrm{Y}$ \\
\hline Connick et al. 2018 & $\mathrm{Y}$ & $\mathrm{Y}$ & $\mathrm{N}$ & $\mathrm{Y}$ & $\mathrm{Y}$ & $\mathrm{Y}$ & $\mathrm{Y}$ & $\mathrm{Y}$ & $\mathrm{Y}$ & $\mathrm{Y}$ & $\mathrm{Y}$ & $\mathrm{Y}$ & $\mathrm{Y}$ & $\mathrm{Y}$ & $\mathrm{Y}$ & $\mathrm{N}$ & $\mathrm{Y}$ \\
\hline Hyde et al. 2017 & Y & $\mathrm{Y}$ & $\mathrm{N}$ & $\mathrm{Y}$ & $\mathrm{Y}$ & $\mathrm{Y}$ & $\mathrm{Y}$ & $\mathrm{Y}$ & $\mathrm{Y}$ & $\mathrm{Y}$ & $\mathrm{Y}$ & $\mathrm{Y}$ & $\mathrm{Y}$ & $\mathrm{Y}$ & $\mathrm{Y}$ & $\mathrm{N}$ & $\mathrm{Y}$ \\
\hline Rosso et al. 2019 & $\mathrm{Y}$ & $\mathrm{Y}$ & $\mathrm{N}$ & $\mathrm{Y}$ & $\mathrm{Y}$ & $\mathrm{Y}$ & $\mathrm{Y}$ & $\mathrm{Y}$ & $\mathrm{Y}$ & $\mathrm{Y}$ & $\mathrm{Y}$ & $\mathrm{Y}$ & $\mathrm{Y}$ & $\mathrm{Y}$ & $\mathrm{Y}$ & $\mathrm{N}$ & $\mathrm{Y}$ \\
\hline Santos et al. 2017 & Y & $\mathrm{Y}$ & $\mathrm{N}$ & $\mathrm{Y}$ & $\mathrm{Y}$ & $\mathrm{Y}$ & $\mathrm{Y}$ & $\mathrm{Y}$ & $\mathrm{Y}$ & $\mathrm{Y}$ & $\mathrm{N}$ & Y & Y & $\mathrm{Y}$ & $\mathrm{Y}$ & $\mathrm{N}$ & Y \\
\hline Vanlandewijck et al. 2011 & $\mathrm{Y}$ & $\mathrm{Y}$ & $\mathrm{N}$ & $\mathrm{Y}$ & $\mathrm{Y}$ & $\mathrm{Y}$ & $\mathrm{Y}$ & $\mathrm{Y}$ & $\mathrm{Y}$ & $\mathrm{Y}$ & $\mathrm{Y}$ & $\mathrm{Y}$ & $\mathrm{Y}$ & $\mathrm{Y}$ & $\mathrm{N}$ & $\mathrm{N}$ & $\mathrm{Y}$ \\
\hline
\end{tabular}

Non-Para sport studies investigating strength impairment

\begin{tabular}{lllllllllllllllllllllll}
\hline Gagnon et al. 2018 & $\mathrm{Y}$ & $\mathrm{Y}$ & $\mathrm{N}$ & $\mathrm{Y}$ & $\mathrm{Y}$ & $\mathrm{Y}$ & $\mathrm{Y}$ & $\mathrm{Y}$ & $\mathrm{Y}$ & $\mathrm{Y}$ & $\mathrm{Y}$ & $\mathrm{Y}$ & $\mathrm{Y}$ & $\mathrm{Y}$ & $\mathrm{Y}$ & $\mathrm{NR}$ & $\mathrm{Y}$
\end{tabular}

Para sport studies investigating coordination impairment

\begin{tabular}{|c|c|c|c|c|c|c|c|c|c|c|c|c|c|c|c|c|c|}
\hline Connick et al. 2016 & $\mathrm{Y}$ & $\mathrm{Y}$ & $\mathrm{N}$ & $\mathrm{Y}$ & $\mathrm{Y}$ & UD & $\mathrm{Y}$ & $\mathrm{Y}$ & $\mathrm{Y}$ & $\mathrm{Y}$ & $\mathrm{Y}$ & $\mathrm{Y}$ & $\mathrm{Y}$ & $\mathrm{Y}$ & $\mathrm{N}$ & $\mathrm{N}$ & $\mathrm{Y}$ \\
\hline Deuble et al. 2016 & $\mathrm{Y}$ & $\mathrm{Y}$ & $\mathrm{N}$ & $\mathrm{N}$ & $\mathrm{N}$ & $\mathrm{N}$ & $\mathrm{Y}$ & $\mathrm{Y}$ & $\mathrm{Y}$ & $\mathrm{Y}$ & $\mathrm{Y}$ & $\mathrm{Y}$ & $\mathrm{Y}$ & $\mathrm{Y}$ & $\mathrm{N}$ & $\mathrm{N}$ & $\mathrm{Y}$ \\
\hline Hogarth et al. 2019 & Y & $\mathrm{Y}$ & $\mathrm{N}$ & $\mathrm{Y}$ & $\mathrm{Y}$ & $\mathrm{Y}$ & $\mathrm{Y}$ & $\mathrm{Y}$ & $\mathrm{Y}$ & $\mathrm{Y}$ & $\mathrm{Y}$ & $\mathrm{Y}$ & $\mathrm{Y}$ & $\mathrm{Y}$ & $\mathrm{N}$ & $\mathrm{N}$ & $\mathrm{Y}$ \\
\hline Roldan et al. 2017 & $\mathrm{Y}$ & $\mathrm{Y}$ & $\mathrm{N}$ & $\mathrm{Y}$ & $\mathrm{Y}$ & Y & $\mathrm{Y}$ & $\mathrm{Y}$ & $\mathrm{Y}$ & $\mathrm{Y}$ & $\mathrm{Y}$ & $\mathrm{Y}$ & $\mathrm{Y}$ & $\mathrm{Y}$ & $\mathrm{Y}$ & $\mathrm{N}$ & $\mathrm{Y}$ \\
\hline
\end{tabular}




\begin{tabular}{|c|c|c|c|c|c|c|c|c|c|c|c|c|c|c|c|c|c|}
\hline Artilheiro et al. 2014 & $\mathrm{Y}$ & $\mathrm{Y}$ & $\mathrm{Y}$ & $\mathrm{Y}$ & $\mathrm{Y}$ & $\mathrm{Y}$ & $\mathrm{Y}$ & $\mathrm{Y}$ & $\mathrm{Y}$ & $\mathrm{Y}$ & $\mathrm{Y}$ & $\mathrm{Y}$ & $\mathrm{Y}$ & $\mathrm{Y}$ & $\mathrm{Y}$ & $\mathrm{N}$ & $\mathrm{Y}$ \\
\hline Bui et al. 2017 & $\mathrm{Y}$ & $\mathrm{Y}$ & $\mathrm{N}$ & $\mathrm{Y}$ & $\mathrm{Y}$ & $\mathrm{Y}$ & $\mathrm{Y}$ & $\mathrm{Y}$ & $\mathrm{Y}$ & $\mathrm{Y}$ & $\mathrm{Y}$ & $\mathrm{Y}$ & $\mathrm{Y}$ & $\mathrm{Y}$ & $\mathrm{N}$ & $\mathrm{N}$ & Y \\
\hline Corben et al. 2010 & $\mathrm{Y}$ & $\mathrm{Y}$ & $\mathrm{N}$ & $\mathrm{Y}$ & $\mathrm{Y}$ & $\mathrm{Y}$ & $\mathrm{Y}$ & $\mathrm{Y}$ & $\mathrm{Y}$ & $\mathrm{Y}$ & $\mathrm{Y}$ & $\mathrm{Y}$ & $\mathrm{Y}$ & $\mathrm{Y}$ & $\mathrm{N}$ & $\mathrm{N}$ & Y \\
\hline Gagnon et al. 2004 & $\mathrm{Y}$ & $\mathrm{Y}$ & $\mathrm{N}$ & $\mathrm{Y}$ & $\mathrm{Y}$ & $\mathrm{Y}$ & $\mathrm{Y}$ & $\mathrm{Y}$ & $\mathrm{Y}$ & $\mathrm{Y}$ & $\mathrm{N}$ & $\mathrm{Y}$ & $\mathrm{Y}$ & $\mathrm{Y}$ & $\mathrm{N}$ & $\mathrm{N}$ & Y \\
\hline $\begin{array}{l}\text { Gagnon et al. } 2018 \\
\text { (Orphanet) }\end{array}$ & $\mathrm{Y}$ & $\mathrm{Y}$ & $\mathrm{N}$ & $\mathrm{Y}$ & $\mathrm{Y}$ & $\mathrm{Y}$ & $\mathrm{Y}$ & $\mathrm{Y}$ & $\mathrm{Y}$ & $\mathrm{Y}$ & $\mathrm{Y}$ & $\mathrm{Y}$ & $\mathrm{Y}$ & $\mathrm{Y}$ & $\mathrm{Y}$ & $\mathrm{N}$ & $\mathrm{Y}$ \\
\hline $\begin{array}{l}\text { Gagnon et al. } 2018 \\
\text { (APMR) }\end{array}$ & $\mathrm{Y}$ & $\mathrm{Y}$ & $\mathrm{N}$ & $\mathrm{Y}$ & $\mathrm{Y}$ & $\mathrm{Y}$ & $\mathrm{Y}$ & $\mathrm{Y}$ & $\mathrm{Y}$ & $\mathrm{Y}$ & $\mathrm{Y}$ & $\mathrm{Y}$ & $\mathrm{Y}$ & $\mathrm{Y}$ & $\mathrm{Y}$ & NR & $\mathrm{Y}$ \\
\hline
\end{tabular}

\section{Para sport studies investigating ROM impairment}

\begin{tabular}{|c|c|c|c|c|c|c|c|c|c|c|c|c|c|c|c|c|c|}
\hline Bjerkefors et al. 2019 & $\mathrm{Y}$ & $\mathrm{Y}$ & $\mathrm{N}$ & $\mathrm{Y}$ & $\mathrm{Y}$ & $\mathrm{Y}$ & $\mathrm{Y}$ & $\mathrm{Y}$ & $\mathrm{Y}$ & $\mathrm{Y}$ & $\mathrm{Y}$ & $\mathrm{Y}$ & $\mathrm{Y}$ & $\mathrm{Y}$ & $\mathrm{Y}$ & $\mathrm{N}$ & $\mathrm{Y}$ \\
\hline Fung et al. 2013 & $\mathrm{Y}$ & $\mathrm{Y}$ & $\mathrm{N}$ & $\mathrm{Y}$ & $\mathrm{Y}$ & $\mathrm{Y}$ & $\mathrm{Y}$ & $\mathrm{Y}$ & $\mathrm{Y}$ & $\mathrm{Y}$ & $\mathrm{Y}$ & $\mathrm{Y}$ & $\mathrm{Y}$ & $\mathrm{Y}$ & $\mathrm{Y}$ & NR & $\mathrm{Y}$ \\
\hline Hyde et al. 2017 & $\mathrm{Y}$ & $\mathrm{Y}$ & $\mathrm{N}$ & $\mathrm{Y}$ & $\mathrm{Y}$ & $\mathrm{Y}$ & $\mathrm{Y}$ & $\mathrm{Y}$ & $\mathrm{Y}$ & $\mathrm{Y}$ & $\mathrm{Y}$ & $\mathrm{Y}$ & $\mathrm{Y}$ & $\mathrm{Y}$ & $\mathrm{Y}$ & $\mathrm{N}$ & $\mathrm{Y}$ \\
\hline Nicholson et al. 2018 & $\mathrm{Y}$ & $\mathrm{Y}$ & $\mathrm{N}$ & $\mathrm{Y}$ & $\mathrm{Y}$ & $\mathrm{Y}$ & $\mathrm{Y}$ & $\mathrm{Y}$ & $\mathrm{Y}$ & $\mathrm{Y}$ & $\mathrm{Y}$ & $\mathrm{Y}$ & $\mathrm{Y}$ & $\mathrm{Y}$ & $\mathrm{Y}$ & $\mathrm{N}$ & $\mathrm{Y}$ \\
\hline Reina et al. 2018 & $\mathrm{Y}$ & Y & $\mathrm{N}$ & $\mathrm{Y}$ & Y & $\mathrm{Y}$ & $\mathrm{Y}$ & $\mathrm{Y}$ & $\mathrm{Y}$ & $\mathrm{N}$ & $\mathrm{Y}$ & $\mathrm{Y}$ & $\mathrm{Y}$ & $\mathrm{Y}$ & $\mathrm{N}$ & NR & $\mathrm{Y}$ \\
\hline
\end{tabular}

Non-Para sport studied investigating ROM impairment

\begin{tabular}{|c|c|c|c|c|c|c|c|c|c|c|c|c|c|c|c|c|c|}
\hline Artilheiro et al. 2014 & $\mathrm{Y}$ & $\mathrm{Y}$ & $\mathrm{Y}$ & $\mathrm{Y}$ & $\mathrm{Y}$ & $\mathrm{Y}$ & $\mathrm{Y}$ & $\mathrm{Y}$ & $\mathrm{Y}$ & $\mathrm{Y}$ & $\mathrm{Y}$ & $\mathrm{Y}$ & $\mathrm{Y}$ & $\mathrm{Y}$ & $\mathrm{Y}$ & $\mathrm{N}$ & $\mathrm{Y}$ \\
\hline TOTAL, n (\%) & $\begin{array}{c}26 \\
(100)\end{array}$ & $\begin{array}{c}26 \\
(100)\end{array}$ & $\begin{array}{c}3 \\
(12)\end{array}$ & $\begin{array}{c}25 \\
(96)\end{array}$ & $\begin{array}{c}25 \\
(96)\end{array}$ & $\begin{array}{c}24 \\
(92)\end{array}$ & $\begin{array}{c}26 \\
(100)\end{array}$ & $\begin{array}{c}26 \\
(100)\end{array}$ & $\begin{array}{c}26 \\
(100)\end{array}$ & $\begin{array}{c}25 \\
(96)\end{array}$ & $\begin{array}{c}24 \\
(92)\end{array}$ & $\begin{array}{c}26 \\
(100)\end{array}$ & $\begin{array}{c}26 \\
(100)\end{array}$ & $\begin{array}{c}26 \\
(100)\end{array}$ & $\begin{array}{c}18 \\
(69)\end{array}$ & $\begin{array}{c}19 \\
(73)\end{array}$ & $\begin{array}{c}26 \\
(100)\end{array}$ \\
\hline
\end{tabular}

justified?; 4) Was the target population clearly identified?; 5) Was the sample frame taken from an appropriate population base so that it closely represented the target population?; 6) Was the selection process likely to select participants that were presentative of the target population?; 8) Were the outcome variables measured appropriate to the aims of the study?; 9) Were the risk factor and outcome variables measured correctly using instruments that had been trialled or published previously?; 10) Is it clear what was used to determine statistical significance and/or precision estimates?; 11) Were the methods sufficiently described to enable them to be repeated?; 12) Were the basic data adequately described?; 15) Were the results internally consistent?; 16) Were the results for the analyses described in the methods, presented?; 17) Were the authors' discussions and conclusions justified by the results?; 18) Were the limitations of the study discussed?; 19) Were there any funding sources or conflicts of interest that may affect the authors' interpretation of the results?; 20) Was ethical approval or consent of participants attained? 


\begin{tabular}{|c|c|c|c|}
\hline Section/topic & $\#$ & Checklist item & $\begin{array}{l}\text { Reported } \\
\text { on page \# }\end{array}$ \\
\hline \multicolumn{4}{|l|}{ TITLE } \\
\hline Title & 1 & Identify the report as a systematic review, meta-analysis, or both. & 1 \\
\hline \multicolumn{4}{|l|}{ ABSTRACT } \\
\hline Structured summary & 2 & $\begin{array}{l}\text { Provide a structured summary including, as applicable: background; objectives; data sources; study eligibility criteria, } \\
\text { participants, and interventions; study appraisal and synthesis methods; results; limitations; conclusions and } \\
\text { implications of key findings; systematic review registration number. }\end{array}$ & 2 \\
\hline \multicolumn{4}{|l|}{ INTRODUCTION } \\
\hline Rationale & 3 & Describe the rationale for the review in the context of what is already known. & $3-5$ \\
\hline Objectives & 4 & $\begin{array}{l}\text { Provide an explicit statement of questions being addressed with reference to participants, interventions, comparisons, } \\
\text { outcomes, and study design (PICOS). }\end{array}$ & 5 \\
\hline \multicolumn{4}{|l|}{ METHODS } \\
\hline Protocol and registration & 5 & $\begin{array}{l}\text { Indicate if a review protocol exists, if and where it can be accessed (e.g., Web address), and, if available, provide } \\
\text { registration information including registration number. }\end{array}$ & 5 \\
\hline Eligibility criteria & 6 & $\begin{array}{l}\text { Specify study characteristics (e.g., PICOS, length of follow-up) and report characteristics (e.g., years considered, } \\
\text { language, publication status) used as criteria for eligibility, giving rationale. }\end{array}$ & $6-7$ \\
\hline Information sources & 7 & $\begin{array}{l}\text { Describe all information sources (e.g., databases with dates of coverage, contact with study authors to identify } \\
\text { additional studies) in the search and date last searched. }\end{array}$ & $5-6$ \\
\hline Search & 8 & $\begin{array}{l}\text { Present full electronic search strategy for at least one database, including any limits used, such that it could be } \\
\text { repeated. }\end{array}$ & $5-6$ \\
\hline Study selection & 9 & $\begin{array}{l}\text { State the process for selecting studies (i.e., screening, eligibility, included in systematic review, and, if applicable, } \\
\text { included in the meta-analysis). }\end{array}$ & $6-7$ \\
\hline Data collection process & 10 & $\begin{array}{l}\text { Describe method of data extraction from reports (e.g., piloted forms, independently, in duplicate) and any processes } \\
\text { for obtaining and confirming data from investigators. }\end{array}$ & 7 \\
\hline Data items & 11 & $\begin{array}{l}\text { List and define all variables for which data were sought (e.g., PICOS, funding sources) and any assumptions and } \\
\text { simplifications made. }\end{array}$ & 7 \\
\hline $\begin{array}{l}\text { Risk of bias in individual } \\
\text { studies }\end{array}$ & 12 & $\begin{array}{l}\text { Describe methods used for assessing risk of bias of individual studies (including specification of whether this was } \\
\text { done at the study or outcome level), and how this information is to be used in any data synthesis. }\end{array}$ & $7-8$ \\
\hline Summary measures & 13 & State the principal summary measures (e.g., risk ratio, difference in means). & N/A \\
\hline Synthesis of results & 14 & $\begin{array}{l}\text { Describe the methods of handling data and combining results of studies, if done, including measures of consistency } \\
\left(\text { e.g., }\left.\right|^{2}\right) \text { for each meta-analysis. }\end{array}$ & $\mathrm{N} / \mathrm{A}$ \\
\hline
\end{tabular}




\begin{tabular}{|c|c|c|c|}
\hline Section/topic & \# & Checklist item & $\begin{array}{l}\text { Reported } \\
\text { on page \# }\end{array}$ \\
\hline Risk of bias across studies & 15 & $\begin{array}{l}\text { Specify any assessment of risk of bias that may affect the cumulative evidence (e.g., publication bias, selective } \\
\text { reporting within studies). }\end{array}$ & $7-8$ \\
\hline Additional analyses & 16 & $\begin{array}{l}\text { Describe methods of additional analyses (e.g., sensitivity or subgroup analyses, meta-regression), if done, indicating } \\
\text { which were pre-specified. }\end{array}$ & $\mathrm{N} / \mathrm{A}$ \\
\hline \multicolumn{4}{|l|}{ RESULTS } \\
\hline Study selection & 17 & $\begin{array}{l}\text { Give numbers of studies screened, assessed for eligibility, and included in the review, with reasons for exclusions at } \\
\text { each stage, ideally with a flow diagram. }\end{array}$ & 8, Fig. 1 \\
\hline Study characteristics & 18 & $\begin{array}{l}\text { For each study, present characteristics for which data were extracted (e.g., study size, PICOS, follow-up period) and } \\
\text { provide the citations. }\end{array}$ & $\begin{array}{l}\text { Tables 1- } \\
3\end{array}$ \\
\hline Risk of bias within studies & 19 & Present data on risk of bias of each study and, if available, any outcome level assessment (see item 12). & Table 4 \\
\hline Results of individual studies & 20 & $\begin{array}{l}\text { For all outcomes considered (benefits or harms), present, for each study: (a) simple summary data for each } \\
\text { intervention group (b) effect estimates and confidence intervals, ideally with a forest plot. }\end{array}$ & $\begin{array}{l}\text { 9-16, } \\
\text { Table 1-3 }\end{array}$ \\
\hline Synthesis of results & 21 & Present results of each meta-analysis done, including confidence intervals and measures of consistency. & $9-16$ \\
\hline Risk of bias across studies & 22 & Present results of any assessment of risk of bias across studies (see Item 15). & $9-16$ \\
\hline Additional analysis & 23 & Give results of additional analyses, if done (e.g., sensitivity or subgroup analyses, meta-regression [see Item 16]). & N/A \\
\hline \multicolumn{4}{|l|}{ DISCUSSION } \\
\hline Summary of evidence & 24 & $\begin{array}{l}\text { Summarize the main findings including the strength of evidence for each main outcome; consider their relevance to } \\
\text { key groups (e.g., healthcare providers, users, and policy makers). }\end{array}$ & $17-23$ \\
\hline Limitations & 25 & $\begin{array}{l}\text { Discuss limitations at study and outcome level (e.g., risk of bias), and at review-level (e.g., incomplete retrieval of } \\
\text { identified research, reporting bias). }\end{array}$ & $23-24$ \\
\hline Conclusions & 26 & Provide a general interpretation of the results in the context of other evidence, and implications for future research. & 25 \\
\hline \multicolumn{4}{|l|}{ FUNDING } \\
\hline Funding & 27 & $\begin{array}{l}\text { Describe sources of funding for the systematic review and other support (e.g., supply of data); role of funders for the } \\
\text { systematic review. }\end{array}$ & 26 \\
\hline
\end{tabular}

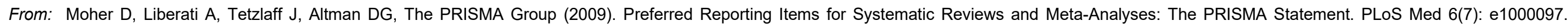
doi:10.1371/journal.pmed1000097 